\title{
CELLULAR MECHANISMS FOR MODULATION OF POSTURE BY OCTOPAMINE AND SEROTONIN IN THE LOBSTER ${ }^{1}$
}

\author{
RONALD M. HARRIS-WARRICK ${ }^{*, 2}$ AND EDWARD A. KRAVITZ $\ddagger$ \\ ${ }^{*}$ Section of Neurobiology and Behavior, Division of Biological Sciences, Cornell University, Ithaca, New York 14853 and \\ $\$$ Department of Neurobiology, Harvard Medical School, Boston, Massachusetts 02115
}

Received May 3, 1983; Revised December 28, 1983; Accepted February 23, 1984

\begin{abstract}
Injection of the monoamines octopamine and serotonin into the hemolymph of lobsters causes them to assume opposing static postures: octopamine causes a tonic extension of all extremities, while serotonin induces a tonic flexion. These amines have been shown previously to act as circulating neurohormones and to cause contraction of isolated exoskeletal muscles. The opposing postures elicited by amine injection do not appear to arise from peripheral actions, however, since serotonin and octopamine have similar effects on both flexor and extensor muscles. Instead, the amines are present within the central nervous system where they are probably released synaptically to activate coordinated patterns of tonic motor activity generating the observed postures. These motor patterns have been recorded from abdominal ganglia and involve the synchronized activation and inhibition of multiple excitatory and inhibitory motoneurons innervating the postural flexor and extensor muscles. These effects can be observed in an isolated abdominal ganglion. To begin a search for the cellular targets of amine action within the central nervous system, we recorded from identified postural motoneurons in abdominal ganglia. In two motoneurons that act to produce postural extension, octopamine reduced and serotinin raised the apparent threshold for action potential generation recorded in the somata. The amines do not significantly affect the resting potential or input resistance of the motoneurons measured in the cell bodies. Although the amine effect on motoneuron excitability could be due to actions directly on the motoneurons, our evidence suggests that at least part of the effect results from activation or inhibition of premotor interneurons: (1) an increase in EPSP frequency is observed in the motoneurons during octopamine superfusion, while a small decrease is observed during serotonin superfusion; (2) the amine effects on action potential threshold are abolished by cobalt ion. These results suggest that octopamine and serotonin have dual effects on posture: within the central nervous system, they act specifically to generate coordinated motor patterns for flexion or extension; as circulating neurohormones, they act nonspecifically to enhance the responses of exoskeletal muscles to motoneuronal activation.
\end{abstract}

Much evidence suggests that coordinated motor activities like locomotion, swimming, and posturing are generated within the central nervous system by local circuits of neurons called central pattern generators (CPGs) (Grillner, 1975a, b, 1981; Kennedy and Davis, 1977; Delcomyn, 1980; Selverston, 1980). Localized in the spinal cord of vertebrates or the distributed ganglia of invertebrates, CPGs can produce a complete motor program in the absence of sensory input. The motor output is usually not invariant, however, and both sensory feedback and descending input from higher CNS structures modulate the

\footnotetext{
1 This work was supported by National Institutes of Health Grants NS-17323 (to R. H.-W.), and NS-07848 and NS-02253 (to E. A. K.). Dr. Margaret $\mathbf{S}$. Livingstone initiated this line of investigation in our laboratory, and we thank her for many helpful discussions. We also thank J. Stillman and J. Filler for technical assistance, and B. Seely, M. Nelson, and R. Flamm for their help in preparing the manuscript. We are grateful to Dr. Michael Johnston for his assistance during experiments on the abdominal neuromuscular junction.

${ }^{2}$ To whom correspondence should be addressed.
}

activity of CPGs to adjust motor output to meet environmental demands (Davis, 1976; Grillner, 1981).

The organization of CPG circuits has been difficult to unravel, due to the complexity of the circuits and multiple levels of interaction between the participating neurons (Selverston, 1980). One aspect of the study of CPGs has been the discovery of compounds that can produce or modulate motor output; biogenic amines are one such group of compounds. Early work showed that $\mathrm{L}$-DOPA, the precursor of dopamine and norepinephrine, induced walking in spinal cats (Grillner, 1969, 1975b), while both L-DOPA and 5-hydroxytryptophan, the precursor of serotonin, activated locomotion in spinal rabbits (Viala and Buser, 1969, 1971). The monoamines serotonin, dopamine, and octopamine are active in many motor circuits in invertebrates (Florey and Florey, 1954; Granzow and Kater, 1977; Livingstone et al., 1980; Kupfermann and Weiss, 1981; Willard, 1981; Augustine et al., 1982; Cooke and Sullivan, 1982). In these simpler invertebrate circuits it is possible to identify the cellular targets of amine action, thereby simplifying the task of understanding the complex mechanisms by which amines modulate activity of motor circuits. 
In the lobster, Homarus americanus, the monoamines serotonin and octopamine are released from neurosecretory regions into the hemolymph (Evans, et al., 1976; Livingstone et al., 1981; Cooke and Sullivan, 1982; see also Sullivan et al., 1979; Sullivan, 1978). Circulating as neurohormones, they have actions upon multiple targets in the lobster, including the exoskeletal muscles (muscle contraction), hemolymph (increased clotting), and heart (increased rate and strength of contraction) (Florey and Florey, 1954; Sullivan and Barker, 1975; Battelle and Kravitz, 1978; Florey and Rathmayer, 1978; Kravitz et al., 1980; Cooke and Sullivan, 1982). Detailed studies of amine action have been performed on the opener muscle of the dactyl of the walking leg in lobsters (Kravitz et al., 1980; for similar studies in crayfish, see Dudel, 1965; Fischer and Florey, 1983). Both serotonin and octopamine (as well as a peptide, proctolin (Schwarz et al., 1980)) interact directly with the muscle to produce a prolonged muscle contracture (Battelle and Kravitz, 1978; Fischer and Florey, 1983). In addition, serotonin acts on motor nerve terminals to enhance transmitter release (Dudel, 1965; Glusman and Kravitz, 1982: Fischer and Florey, 1983), thereby increasing the strength of nerve-cvoked contractions.

In an earlier paper (Livingstone et al., 1980), we reported that injection of octopamine or serotonin into the hemolymph of freely moving lobsters caused them to assume characteristic and static postures. Octopamine injection induced a posture of hyperextension of the abdomen, claws, and walking legs, whereas serotonin activated a pronounced flexion of all extremities. Preliminary results suggested that the amines produced these postures by acting within the CNS to release coordinated patterns of activation and inhibition of motoneurons innervating postural muscles. In this paper we present a more detailed analysis of the possible cellular targets of amine action in producing postural flexion and extension. These results show that the hormonal actions of the amines on peripheral exoskeletal muscles are similar on flexor and extensor muscles and thus do not provide specificity for the assumption of opposing postures. Instead, specificity arises by opposing actions of the amines on the excitability of neurons located within central ganglia.

\section{Materials and Methods}

Lobsters $(0.5 \mathrm{~kg})$ were purchased locally and were maintained in holding tanks in artificial sea water (Instant Ocean, Aquarium Systems, Mentor, $\mathrm{OH}$ ) at 12 to $14^{\circ} \mathrm{C}$. All chemicals were purchased from Sigma Chemical Co., St. Louis, MO. Lobster saline had the following composition: $462 \mathrm{mM} \mathrm{NaCl}, 16 \mathrm{mM} \mathrm{KCl}, 26 \mathrm{mM} \mathrm{CaCl}_{2}, 8 \mathrm{mM} \mathrm{MgCl}_{2}, 11 \mathrm{mM}$ glucose, $10 \mathrm{~mm}$ Tris, $10 \mathrm{~mm}$ maleic acid, pH adjusted to 7.4 with $\mathrm{NaOH}$. Physiological experiments were performed at 9 to $12^{\circ} \mathrm{C}$, and saline was superfused over the preparations at $3 \mathrm{ml} / \mathrm{min}$.

Peripheral neuromuscular junction recordings. The opener muscle of the dactyl of the walking leg was dissected as described previously (Otsuka et al., 1966). The muscle was set up for tension recording using a Grass FT.03C force transducer as described by Battelle and Kravitz (1978). Other muscles were dissected from the walking leg and treated in an identical manner, except that inhibitory axons were not separated from the nerve bundles containing excitatory axons: instead, gradually increasing voltage pulses were delivered to the mixed motor nerves until single units were activated. The superficial flexor and extensor muscles of the abdomen were dissected as described in the next section, except that the ganglia containing the motoneurons innervating these muscles were removed. For the extensor muscles, only the most medial bundle of muscle fibers were used in these studies. For studies of the effects of amines on amplitudes of evoked excitatory junctional potentials (EJPs), muscle fibers were impaled with low resistance (2 to 10 megohms) microelectrodes filled with $2 \mathrm{M}$ potassium acetate. Motor nerves were stimulated through a suction electrode with 0.5 -msec pulses at a frequency of $0.5 \mathrm{~Hz}$. Evoked EJPs were signal-averaged by a Digital PDP 11/03 microcomputer. For some experiments, short trains of stimuli $(80$ msec, $150 \mathrm{~Hz}$ ) were delivered to nerves to study small, rapidly facilitating EJPs.
Ventral nerve cord recording. Abdominal posture in the lobster is generated by two bilaterally symmetrical pairs of thin muscles on the dorsal and ventral sides of the abdomen. Each muscle is segmentally innervated by one inhibitory and five excitatory motoneurons whose axons run in the second (extensor) or superficial branch of the third (flexor) nerve roots from each abdominal ganglion. Thus, posture of an abdominal segment is specified by the pattern of tonic activity of 24 postural motoneurons in each ganglion. To monitor this pattern of postural motor activity, we combined extracellular recordings of motoneuron spike activity from the appropriate nerve root with intracellular recordings from both the postural muscles, and from the somata of the postural motoneurons.

The standard preparation used in these experiments was the abdominal section of the ventral nerve cord (abdominal ganglia 1 to 6) with intact motor roots to the postural flexor muscles of the first and second abdominal segments. To obtain this preparation, the abdomen was removed from an animal and the ventral nerve cord and postural flexor muscles were exposed by removing an overlying strip of ventral cuticle. All nerve roots were severed except the superficial branch of the third root, innervating the tonic flexor muscles. The thin postural flexor muscles on one side of the abdomen were freed by dissection from the main muscle mass, and the nerve cord-muscle preparation was pinned down in a Sylgard dish. The first and second abdominal ganglia were desheathed on both the dorsal and ventral surfaces to enhance perfusion of amines into the neuropil. Neuronal somata were exposed by blowing away a superficial cellular covering with a gentle stream of cold saline. Extracellular recordings were made en passant from the superficial third roots; the identities of the five excitatory and one inhibitory motoneurons were determined from the amplitudes of the extracellular spikes (see, for example, Fig. 6) and verified by intracellular recordings from postural flexor muscle fibers. These are labeled $\mathrm{Fl}$ to $\mathrm{F} 6$ in order of increasing amplitude; F5 is the inhibitory motoneuron. In some experiments we dissected a preparation in which the postural extensor muscles were left attached through the second root to the ventral nerve cord. In this preparation the motor innervation of postural extensor muscles remains intact. In addition, sensory afferents from the stretch receptor organs that lie beneath the postural extensor muscles and afferents from the exoskeleton are retained. This complicated the recordings from second roots with these preparations; therefore we did not attempt to identify individual motor units in the peripheral branch of the second roots. More often, activity of extensor motoneurons was measured with suction electrode recordings from the cut second roots emerging from the ganglion. Although the second roots contain motor axons to both superficial postural and deep phasic extensor muscles, our earlier study (Livingstone et al., 1980) showed that amines do not activate the motoneurons innervating the phasic extensor muscles; therefore, second root recordings should only show activation of units to the postural extensor muscles.

Soma recordings from identified motoneurons. Individual neuronal somata are readily visualized on the ventral surface of desheathed abdominal ganglia (Otsuka et al., 1967). We recorded from two identified motoneurons: F5, the peripheral inhibitor of postural flexor muscles (called Il by Otsuka et al., 1967) and M15, one of the five excitatory motoneurons to postural extensor muscles (Barker et al., 1972). These motoneurons were identified morphologically by their location in the ganglia and physiologically by (1) antidromic stimulation from the appropriate nerve roots and (2) determination of identical thresholds for action potential generation in the neuron and EJP or inhibitory junction potential (IJP) in the appropriate muscle upon current injection into the cell bodies.

For determination of the I/V relationship and threshold for generation of action potentials, cell bodies of the motoneurons were penetrated with two microelectrodes ( 20 to 40 megohms, filled with $2 \mathrm{M}$ potassium acetate), one for passing current, the other for recording the resulting polarization of the membrane. To determine the input resistance, long steps of current were injected $(100 \mathrm{msec})$, to allow the membrane potential to stabilize at a new value, and the voltage was recorded at the end of the current pulse. The threshold depolarization in the soma for action potential generation was determined by slowly increasing the strength of depolarizing current until a retrograde action potential was recorded in the soma. An average of four to six determinations were used for each point.

Measurement of octopamine and serotonin in abdominal nerve cord. The abdominal nerve cord was dissected in ice-cold saline. All nerve roots and adherent connective tissue external to the sheath were 
removed. The first two ganglia were cut away from the connectives between them, and these were separately pooled for amine determination. 'The tissue was blotted, weighed, and resuspended in homogenization buffers: for serotonin determination, $300 \mu \mathrm{l}$ of $0.1 \mathrm{M} \mathrm{IIClO}_{4}, 0.4$ $\mathrm{mM} \mathrm{NaHSO}_{3}$, pH 1.4, was used, while for octopamine, 50 to $100 \mu \mathrm{l}$ of cold Tris- $\mathrm{HCl}, \mathrm{pH} 9.8$, was added. The tissue was homogenized with a ground glass homogenizer on ice and centrifuged at $10,000 \times g$ to remove insoluble proteins and debris. Endogenous octopamine was determined by the radioenzymatic method of Molinoff et al. (1969). In this method, a $\left[{ }^{3} \mathrm{H}\right]$ methyl group is transferred from $S$-adenosylmethionine to endogenous octopamine, forming $\left[{ }^{3} \mathrm{H}\right]$ synephrine which is extracted and counted. Endogenous serotonin was determined by high performance liquid chromatography (HPLC) with electrochemical detection at $+0.65 \mathrm{~V}$ (LC4-A amperometric detector, Bio-Analytical Systems, West Lafayette, IN). Separations were carried out using a Biophase ODS reverse phase column (Bio-Analytical Systems), with $0.15 \mathrm{M}$ monochloroacetic acid:9\% methanol:2.5 mM EDTA, $0.1 \mathrm{~mm}$ sodium octyl sulfate, $\mathrm{pH} 3.0$, as the mobile phase. Tissue extracts included $2 \mathrm{ng}$ of hydroxybenzylamine as a calibration standard for elution times from the column. To identify endogenous serotonin in the extract, the elution profile was compared to that of authentic serotonin. In addition, serotonin was added to the extract to verify coelution of the endogenous compound and serotonin. For each assay, the oxidation voltage was varied over the range of 0.5 to $0.65 \mathrm{~V}$, to determine the oxidation potential for authentic serotonin and to verify the identity of the endogenous compound co-eluting with authentic serotonin. Standard curves of current versus authentic serotonin were used to quantitate the endogenous serotonin content. Such curves were linear over the range of 15 to $10,000 \mathrm{fmol}$ of serotonin.

\section{Results}

\section{Effects of serotonin and octopamine at the neuromuscular junction}

The generation of postural flexion by serotonin and postural extension by octopamine (Livingstone et al., 1980) could be due to either peripheral or central actions of the amines. Peripherally, octopamine and serotonin could have opposite effects directly on flexor and extensor muscles. Centrally, the amines could selectively affect the coordinated firing pattern of motoneurons producing extension or flexion. Hormonal actions of serotonin and octopamine on certain peripheral exoskeletal muscles have already been examined (Battelle and Kravitz, 1978: Florey and Rathmayer, 1978; Glusman and Kravitz, 1982; Breen and Atwood, 1983; Fischer and Florey, 1983). In our first set of experiments, we looked for differential or opposing hormonal effects of serotonin and octopamine on three pairs of antagonistic exoskeletal muscles: (1) the opener and closer muscles of the dactyl of the walking legs; (2) the flexor and extensor muscles in the meropodite segment of the walking legs; and (3) the abdominal superficial flexor and extensor muscles that are responsible for tonic posture of the abdomen. In each muscle, we monitored the effects of amines on muscle tension and on the amplitude of nerve-evoked EJPs or IJPs recorded intracellularly in the muscle fibers.

Opener and closer muscles of the dactyl of the walking leg. Earlier work by Battelle and Kravitz (1978) showed that serotonin and octopamine induce long-lasting contractures of the opener muscle in the absence of nerve stimulation. The threshold for serotonin action $\left(5 \times 10^{-9} \mathrm{M}\right)$ is over an order of magnitude lower than for octopamine $\left(2 \times 10^{-7} \mathbf{M}\right)$. Both amines also caused contractures of the closer muscle. Somewhat higher concentrations of amines were required in the closer muscle $\left(10^{-7}\right.$ to $\left.10^{-6} \mathrm{M}\right)$, but serotonin was still about an order of magnitude more potent than octopamine ( $n=3$, data not shown). Detailed studies by Glusman and Kravitz (1982) showed that serotonin also has presynaptic effects at opener neuromuscular junctions: it enhances transmitter release from both excitatory and inhibitory nerve terminals resulting in increases in the amplitudes of EJPs and IJPs. In contrast, octopamine had no detectable effect on EJP or IJP amplitude in this muscle under normal experimental conditions. Octopamine does increase EJP amplitude in the crayfish opener muscle preparation (Florey and Rathmayer, 1978; Breen and Atwood, 1983), and in the presence of 3-isobutyl-1-methylxanthine (an inhibitor of the enzyme phosphodiesterase), a small increase in EJP amplitude can be observed at the lobster opener neuromuscular junction (M. Goy, unpublished data). Observations of the closer muscle showed similar patterns: serotonin $\left(10^{-7}\right.$ to $\left.10^{-8} \mathrm{M}\right)$ increased the amplitude of nerve-evoked EJPs, but octopamine at high concentrations $\left(10^{-5} \mathrm{M}\right)$ had no detectable effect ( $n=4$, data not shown. The resting potential and membrane input resistance of muscle fibers were not reproducibly affected by either amine.

Flexor and extensor muscles of the meropodite of the walking leg. The meropodite flexors and extensors are responsible for the major postural positioning of the walking legs, and they were examined next. Unlike the opener and closer muscles, neither serotonin nor octopamine altered the resting tension of these muscles $(n=7)$. However, nerve-evoked EJPs were altered, and the pattern was similar to that seen with the opener and closer muscles. The meropodite flexor and extensor muscles are innervated by one inhibitory and several (four for flexor, two for extensor) excitatory axons. The lowest threshold axons in the nerves that innervate each of these muscles produce very small EJPs that show dramatic facilitation with brief periods of high frequency stimulation $(150 \mathrm{~Hz}, 80 \mathrm{msec}$ trains). With both muscles, serotonin $\left(4 \times 10^{-7} \mathrm{M}\right)$ increased the amplitude of these small EJPs. For flexors, the serotonininduced enhancement of EJP amplitude varied from $180 \%$ to $320 \%(n=3)$. Similar results were seen in the extensors $(n=$ $2)$. In both muscles, octopamine $\left(5 \times 10^{-6} \mathbf{M}\right)$ had no effect on the amplitude of these EJPs $(n=4)$. If the strength of stimulation to the nerve bundles innervating the two muscles is increased, second axons are activated that give much larger EJPs to a single stimulus. Again, with both flexor and extensor muscles, serotonin $\left(4 \times 10^{-7} \mathrm{M}\right)$ increased the amplitude of these EJPs by $212 \%$ to $270 \%(n=5)$. Octopamine $\left(5 \times 10^{-6}\right.$ M) had no effect on the amplitude of the larger EJPs in either muscle $(n=4)$. Again, neither serotonin nor octopamine affected the resting membrane potential or input resistance in these muscle fibers.

Superficial flexor and extensor muscles of the abdomen. The most obvious postural changes caused by amine injection into intact animals involved flexion or extension of the abdomen (Livingstone et al., 1980). The final group of muscles we examined, therefore, were the superficial flexor and extensor muscles responsible for the maintenance of posture of the abdomen (Page, 1982). Neither serotonin nor octopamine caused a reproducible change in the resting tension in either superficial flexor or extensor muscles (Fig. 1). These experiments were repeated under several experimental conditions: (a) picrotoxin $\left(10^{-5} \mathrm{M}\right)$ was added to block the possible actions of the inhibitory neurotransmitter, $\gamma$-aminobutyric acid (GABA); (2) very high concentrations of amines were used $\left(10^{-6} \mathrm{M}\right.$ serotonin or $10^{-5} \mathrm{M}$ octopamine $)$; (3) muscles were artificially depolarized by superfusion with saline containing 1.25 times the normal potassium. In the entire series of experiments, the resting muscle tension was unaffected by octopamine or serotonin. In contrast, nerve-evoked contractions were increased during superfusion of both octopamine and serotonin (Fig. 1). In the superficial flexor muscles, octopamine $\left(5 \times 10^{-6}\right.$ M) enhanced nerve-evoked contraction by $300 \pm 170 \%$ (SD: $n$ $=6$, range, $150 \%$ to $521 \%)$; serotonin $\left(2 \times 10^{-7} \mathrm{M}\right)$ caused an increase of $845 \% \pm 90 \%$ ( $\mathrm{SD} ; n=7$, range, $695 \%$ to $905 \%$ ). In the superficial extensor muscles, changes of similar magnitude were observed (Fig. 1). In several experiments with the superficial extensor muscles, direct electrical stimulation of the muscle was also used to activate the preparation. In these cases, 


\section{A. FLEXOR}

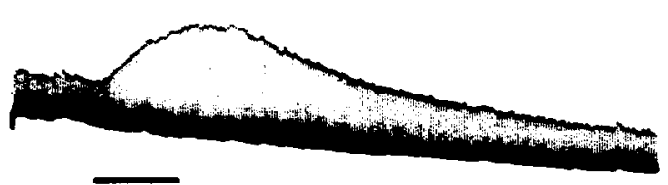

Oct

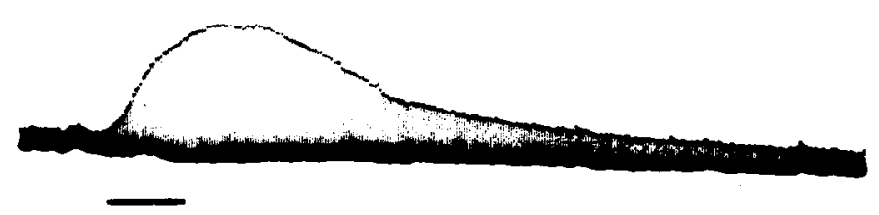

5-HT

\section{$10^{1}$}

\section{B. EXTENSOR}
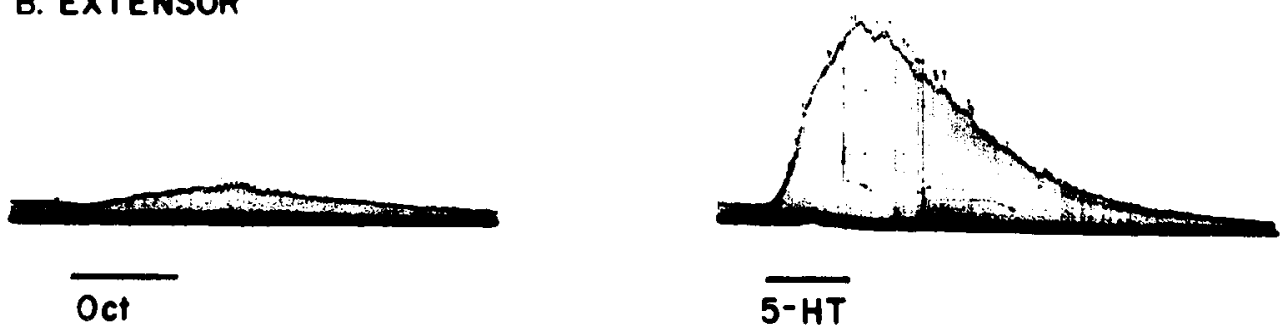

Figure 1. Effects of serotonin and octopamine on muscle tension and nerve-evoked contractions in abdominal postural muscles. $A$, Superficial flexor muscles. Muscle tension was recorded with a Grass FT.03 force transducer. The tension was adjusted to optimize the nerve-evoked contraction and, therefore, was not quantified. The superficial third root innervating the muscle was stimulated at 20 -sec intervals at supramaximal voltage, and the nerve-evoked contraction was recorded as an upward deflection. The perfusing saline contained picrotoxin (10 $\left.0^{-5} \mathrm{M}\right)$ to block inhibitory transmission. At the times indicated, octopamine $\left(5 \times 10^{-6} \mathrm{M}\right)$ and serotonin $\left(2 \times 10^{-7} \mathrm{M}\right)$ were superfused over the preparation. $B$, Superficial extensor muscles. The second root was stimulated every $10 \mathrm{sec}$; octopamine $\left(5 \times 10^{-6} \mathrm{M}\right)$ and serotonin $\left(10^{-7} \mathrm{M}\right)$ were added at the times shown.

serotonin increased the amplitude of the electrically evoked contraction, suggesting a direct effect of serotonin on the muscle. However, the effect was much smaller in magnitude than with nerve-evoked contraction. We suspected, therefore, that, as with the limb muscles, sume large part of the anineinduced enhancement of nerve-evoked contractions results from an increase in transmitter release from motoneuron nerve terminals. The flexor and extensor muscles on one side of the abdomen are each innervated by one inhibitory and five excitatory axons from each abdominal ganglion. These axons can be recruited by increasing the stimulation voltage on the nerve roots innervating the muscles. The effects of octopamine and serotonin on the three lowest threshold flexor motoneurons are shown in Figure 2. Both serotonin and octopamine enhanced the amplitude of the F6 and F4 EJPs, as well as the IJP elicited upon stimulation of F5. The threshold concentration for serotonin action was about $10^{-8} \mathrm{M}$, whereas octopamine was active at concentrations higher than $10^{-7} \mathrm{M}$. Serotonin, at saturating concentrations $\left(2 \times 10^{-7} \mathrm{M}\right.$ to $\left.10^{-6} \mathrm{M}\right)$, caused a 50 to $130 \%$ increase in the EJP and IJP amplitudes $(n=9)$, whereas octopamine at higher concentrations $\left(1\right.$ to $\left.5 \times 10^{-7} \mathrm{M}\right)$ elicited a smaller increase (30 to $40 \%)(n=14)$. The amines also enhanced the amplitudes of EJPs in the superficial extensor muscles (Fig. 3). The lowest threshold axon elicited a small, highly facilitating EJP: serotonin $\left(1\right.$ to $\left.2 \times 10^{-7} \mathrm{M}\right)$ doubled the amplitude of this EJP, whereas octopamine $\left(10^{-6} \mathrm{M}\right)$ caused a 20 to $30 \%$ increase in EJP amplitude ( $n=5$; data not shown). We also tested amine effects on the EJP evoked by a second excitatory axon, with similar results (Fig. 3). Thus, serotonin and octopamine enhanced the amplitudes of all of the EJPs and IJPs we tested on both superficial flexor and extensor muscles: in each preparation, serotonin was active at lower concentrations and elicited a greater maximal effect than did octopamine. Again, neither amine affected the resting potential or membrane input resistance as measured with hyperpolarizing current pulses in abdominal flexor or extensor muscles (Figs. 2 and 3).

Table I summarizes the results of the effects of octopamine and serotonin on the three pairs of flexor-extensor muscles we have examined. The amines have somewhat different profiles of modulation in different muscle pairs. The reasons for these differences between muscle pairs are not known. However, our data show that there is no opposition or differential effect of either amine on flexors or extensors within any of the muscle pairs we tested. Whenever an amine has an effect on one muscle of a pair, it has the same effect on the opposing muscle. Thus, the opposing postures observed upon injection of octopamine and serotonin into freely moving lobsters (Livingstone et al., 1980) are not likely to be explained by differential peripheral effects of the amines on flexor or extensor muscles themselves, or on transmitter release from motoneuron nerve terminals on the muscles.

\section{Central pattern activation by octopamine and serotonin}

We next examined the ability of amines to selectively activate coordinated patterns of motoneuron activity to generate flexion or extension. The isolated abdominal nerve cord with attached postural muscles was chosen for these studies, both because the behavioral effects of octopamine and serotonin are most dramatic in the abdomen (Livingstone et al., 1980) and because the axons of motoneurons innervating postural flexor and extensor muscles are conveniently segregated in the superficial third and the second roots, respectively. Most experiments have been done with the first and second abdominal ganglia. We did not notice any significant differences in amine effects between these ganglia. In several experiments, we recorded from nerves innervating the phasic deep flexor and extensor muscles. These 
A
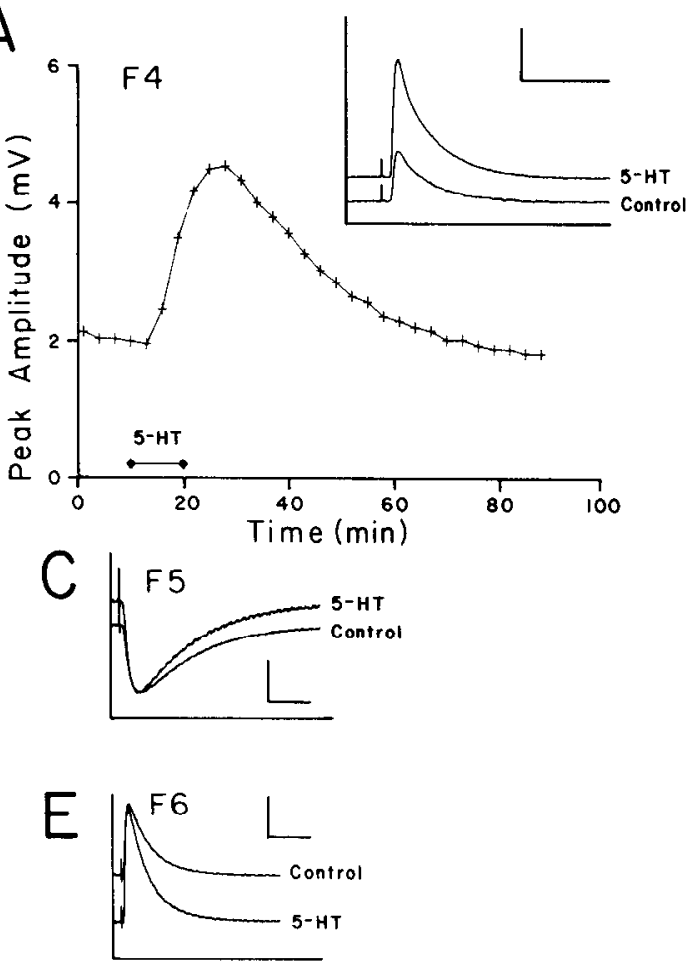

$\mathrm{B}$
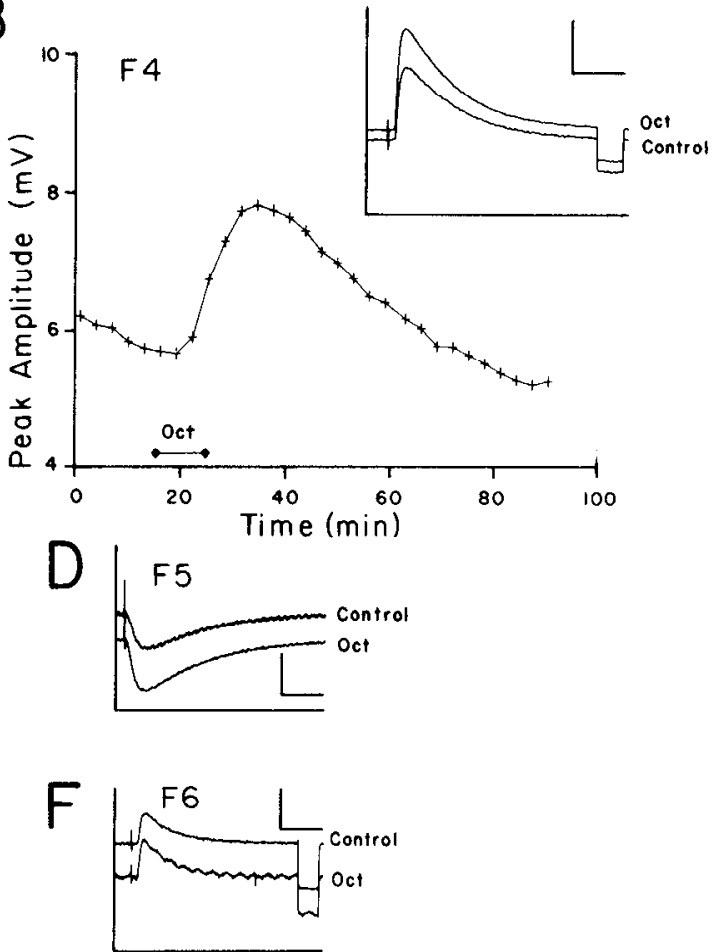

Figure 2. Effect of serotonin (left) and octopamine (right) on EJPs and IJPs recorded in abdominal postural flexor muscles upon stimulation of identified motoneuron axons. The superficial branch of the third root, innervating the postural flexor muscles, was stimulated by brief $(0.5$ $\mathrm{msec}$ ) pulses with a bipolar suction electrode. With increasing stimulation voltage, the order of activation of motoneuron axons is F6, F5, F4. F5-evoked IJPs were recorded in muscle fibers lacking innervation by F6. F4-evoked EJPs were recorded in muscle fibers lacking F6 innervation and in the presence of $10^{-5} \mathrm{M}$ picrotoxin, which completely abolished the F5 IJP. Axons were stimulated at $0.5 \mathrm{~Hz}$, and 30 evoked responses were collected and signal-averaged by a PDP 11-03 microcomputer. $A$ and $B$ show the change in peak amplitude of the F4-evoked FuJP with time and amine addition; typical examples of averaged EJPs before and during amine application are shown in the insets. The time courses of amine effects on F5-evoked IJPs and F6-evoked EJPs were similar to those shown for F4. The drug concentrations and time and amplitude markers are as follows: $A: \mathrm{F} 4,10^{-6} \mathrm{M}$ serotonin, $2 \mathrm{mV}$ and $50 \mathrm{msec} ; B: \mathrm{F} 4,5 \times 10^{-6} \mathrm{M}$ octopamine, $4 \mathrm{mV}$ and $50 \mathrm{msec} ; C: \mathrm{F} 5,2 \times 10^{-7} \mathrm{M}$ serotonin, $2 \mathrm{mV}$ and $100 \mathrm{msec} ; D: \mathrm{F} 5,5 \times 10^{-6} \mathrm{M}$ octopamine, $2 \mathrm{mV}$ and $100 \mathrm{msec} ; E: \mathrm{F} 6,2 \times 10^{-7} \mathrm{M}$ serotonin, $5 \mathrm{mV}$ and $100 \mathrm{msec} ; F: \mathrm{F} 6,10^{-5} \mathrm{M}$ octopamine, 1 $\mathrm{mV}$ and $50 \mathrm{msec}$. In $B$ (inset) and $F$, small hyperpolarizing pulses were injected through the recording electrode to monitor the input resistance of the muscle; this was unaffected by either amine.

muscles mediate rapid movements and are not normally involved in posture. The nerves innervating the phasic muscles were silent at rest and were not activated by either octopamine or serotonin.

Effects of octopamine. Octopamine activated to a coordinated motor output from the isolated abdominal nerve cord that would lead to postural extension of the abdomen. This motor pattern consisted of a simultaneous tonic activation of postural extensor muscles and tonic inhibition of postural flexors. The postural flexor muscles were inhibited by (1) reduced rates of firing of four of the five excitatory motoneurons and (2) an increased rate of firing of the single peripheral inhibitory neuron to these muscles. At the same time, the postural extensor muscles were activated by (1) enhanced firing of multiple excitatory motoneurons and (2) decreased firing of the single peripheral inhibitory neuron to these muscles.

The effect of octopamine on individual motoneurons innervating the postural flexor muscles is shown in Figure 4. In Figure $4 A$ a typical time course of the effects of octopamine on spontaneous spike frequency of these motoneurons is shown. These effects varied somewhat between experiments: a particularly dramatic example is shown in Figure $4 B$ (intracellular recordings of EJPs and IJPs from a postural flexor muscle fiber). The strongest effect of octopamine was an activation of F5, the peripheral inhibitor of postural flexor muscles. In every experiment ( 9 of 9 ), octopamine increased the spike frequency of $\mathrm{F} 5$ by at least $50 \%$, resulting in a tonic inhibition of the flexor muscle. Octopamine also decreased the spike frequency of most of the five excitatory motoneurons innervating the slow flexor muscle on each side of the abdomen. These have been named in order of increasing spike amplitude in extracellular recordings of the superficial third root (Evoy and Kennedy, 1967; Thompson and Page, 1982) and fall into three functional categories. (1) $\mathrm{Fl}$ and $\mathrm{F} 2$ are tonically active and usually elicit small EJPs. Octopamine always decreased the spike frequency of these motoneurons, but the average effect was slight, leading to a decrease of less than $50 \%$ ( 7 of 9 ). In two experiments, F1 and F2 were completely silenced (Fig. $4 B$ ). (2) F3 and F4 are phasically active and usually elicit larger EJPs than do the smaller tonic units. These motoneurons were always strongly inhibited by octopamine (Fig. $4 A$ ), and in four of nine experiments they were completely silenced during octopamine superfusion. (3) F6 has the largest extracellular action potential, fires phasically, and generates a small, highly facilitating EJP in most postural flexor muscles. Unlike the other four excitatory flexor motoneurons, the spike frequency of F6 was not consistently affected by octopamine. In five of nine experiments, it was weakly to strongly inhibited (including two cases of total suppression of spiking) (Fig. $4 B$ ) but in four of nine experiments it was either unaffected or excited by octopamine (see, for example, Fig. 6). Thus, octopamine inhibited postural flexor muscles by decreasing the spike frequency of the excitatory motoneurons Fl to F4 (but not F6) and simultaneously activating the peripheral inhibitory neuron, F5. In two experi- 

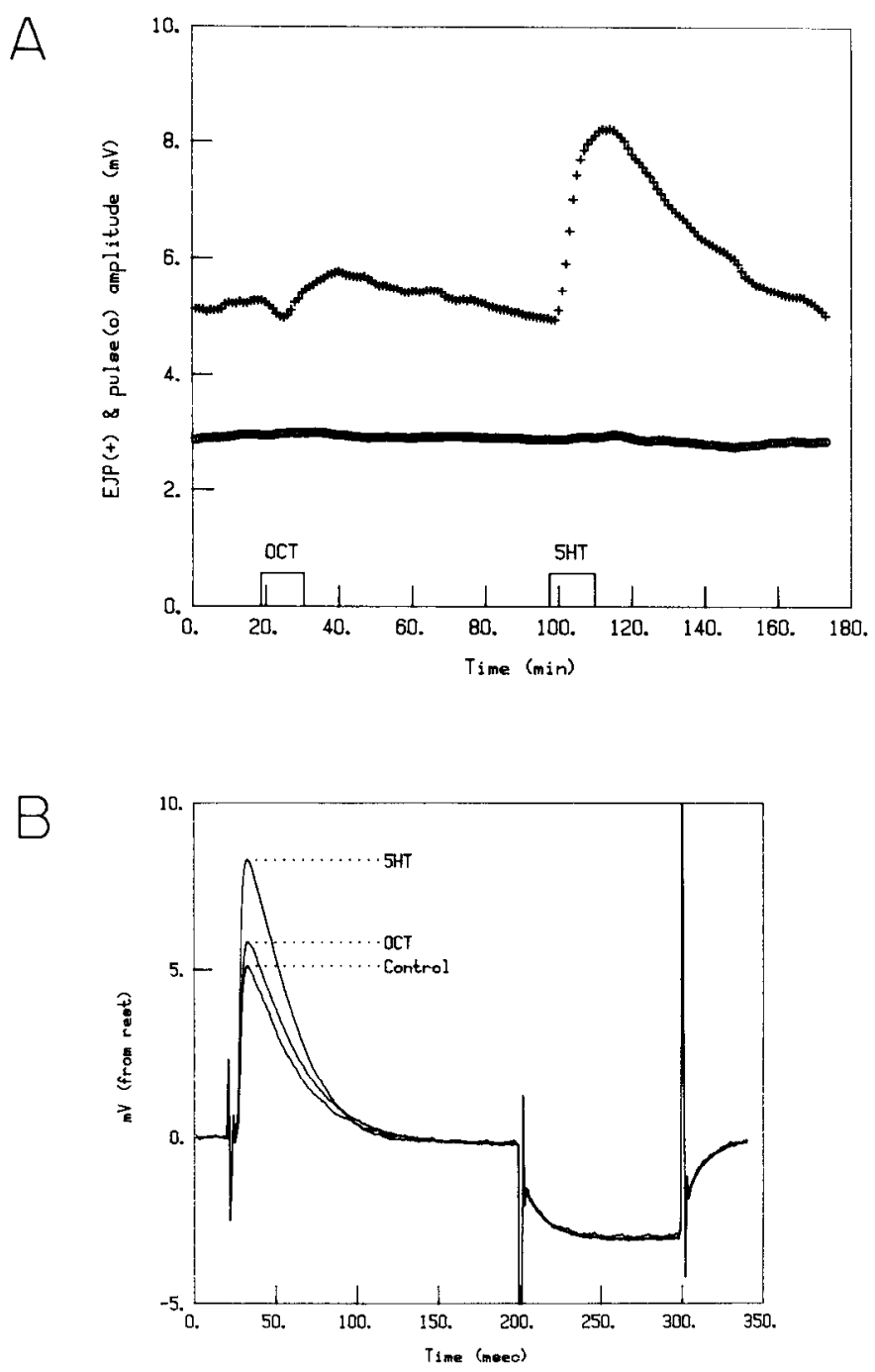

Figure 3. Effects of serotonin and octopamine on nerve-evoked EJPs and muscle input resistance in abdominal postural extensor muscles. The superficial branch of the second root was stimulated at $0.2 \mathrm{~Hz}$ with increasing voltage until a large EJP was evoked (a much smaller EJP was evoked at lower thresholds and acted identically to the large EJP). Octopamine (OCT, $\left.5 \times 10^{-7} \mathrm{M}\right)$ and serotonin $\left(5 \mathrm{HT}, 10^{-7} \mathrm{M}\right)$ were bath-applied at the times indicated. Hyperpolarizing current pulses $(100 \mathrm{nA})$ were injected from a second electrode to monitor muscle input resistance. $A$, Time course of $\mathrm{EJP}(+)$ and hyperpolarizing pulse $(O)$ amplitudes. Each point represents the average amplitude recording during a 5-min period of nerve stimulation at $0.2 \mathrm{~Hz}$, shifted by $1 \mathrm{~min}$ from the previous point. $B$, Sample averaged traces of EJPs and hyperpolarizing pulses recorded under control conditions and at the times of peak response to octopamine and serotonin.

ments, (one of which is shown in Fig. $4 B$ ), this pattern was absolute at the peak of the octopamine response: the inhibitory neuron F5 fired tonically, and all excitatory input was completely silenced.

In contrast to its inhibitory effects on motor output to flexor muscles, octopamine caused strong activation of the postural extensor muscles. The time course of the effect of octopamine on the peripheral inhibitory neuron (E5) and on unidentified excitatory motoneurons producing large and small EJPs in extensor muscles is shown in Figure $5 A$, and the maximal effect of octopamine in this experiment is shown in Figure $5 B$. At rest, postural extensor muscles receive relatively little spontaneous input in our in vitro preparation. Bath application of octopamine produced a strong activation of excitatory extensor
TABLE I

Summary of effects of serotonin and octopamine at peripheral neuromuscular junctions

\begin{tabular}{|c|c|c|c|c|}
\hline \multirow[b]{2}{*}{ Muscle } & \multicolumn{2}{|c|}{ Octopamine } & \multicolumn{2}{|c|}{ Serotonin } \\
\hline & $\begin{array}{c}\text { Muscle } \\
\text { Contracture }\end{array}$ & $\begin{array}{c}\text { EJP } \\
\text { Amplitude }\end{array}$ & $\begin{array}{c}\text { Muscle } \\
\text { Contracture }\end{array}$ & $\begin{array}{c}\text { EJP } \\
\text { Amplitude }\end{array}$ \\
\hline \multicolumn{5}{|l|}{ Abdomen } \\
\hline Superficial flexor & - & + & - & ++ \\
\hline Superficial extensor & - & + & - & ++ \\
\hline \multicolumn{5}{|l|}{ Meropodite (walking leg) } \\
\hline Flexor & - & - & - & ++ \\
\hline Extensor & - & - & - & ++ \\
\hline \multicolumn{5}{|l|}{ Dactyl (walking leg) } \\
\hline Opener & + & $-{ }^{a}$ & ++ & ++ \\
\hline Closer & + & - & ++ & ++ \\
\hline
\end{tabular}

${ }^{a}$ A small increase in amplitude is seen in the presence of 3-isobutylL-methylxanthine, an inhibitor of the enzyme phosphodiesterase (M. Goy, upublished data).

motoneurons: in 10 of 13 preparations, the frequency of large EJPs recorded in extensor muscles increased by greater than $50 \%$; the frequency of small EJPs increased by more than $50 \%$ in every preparation in which these units were spontaneously active (8 of 13 preparations) (Fig. $5, A$ and $B$ ). It was more difficult to determine the effects of octopamine on the peripheral inhibitor, E5, since in most preparations it was silent under control conditions and remained silent during octopamine superfusion (11 of 13 preparations). When it was spontaneously active (Fig. 5, $A$ and $B$ ), octopamine silenced it (2 of 13 experiments).

In some experiments, the isolated nerve cord was used without attached muscles. In this simpler preparation, spontaneous activity in motoneurons was somewhat depressed compared to more intact preparations. This was particularly true of extensor motoneurons, which tended to be completely silent in the absence of sensory feedback (see Control, Fig. $6 A$ and $B$ ). However, even in these reduced preparations, octopamine activated a coordinated motor pattern for extension. In the experiment shown in Figure $6 A$, for example, octopamine activated multiple excitatory postural motoneurons in the extensor root, but it did not activate the peripheral extensor inhibitor, E5 (E5 was identified by its activation by command fibers for postural flexion). At the same time, octopamine activated the flexor inhibitor, F5, and silenced the excitatory axons F3 and F4 to the postural flexor muscles (Fig. 6A); as described above, it had little effect on excitatory motoneuron F6. These experiments show that the tonic motor patterns generated by octopamine arise from neuronal interactions within the abdominal nerve cord and do not require sensory feedback for their organization.

Effects of serotonin. The effects of serotonin on motor output from the abdominal nerve cord were not as clear as those of octopamine. In some experiments (Figs. $4 D$ and $5 D$ ), serotonin activated a coordinated motor pattern exactly opposite to that evoked by octopamine. Postural flexor muscles were activated by (1) increased activity of some of the excitatory flexor motoneurons and (2) decreased activity of the peripheral inhibitory motoneuron, whereas postural extensor muscles were inhibited by (1) enhanced firing of the peripheral inhibitory neuron and ( 2 ) reduced firing of unidentified excitatory extensor motoneurons. However, considerable variability in the action of serotonin was observed, and in the majority of experiments serotonin elicited only part of this coordinated motor pattern.

The effects of serotonin on identified motoneurons to postural flexor muscles are shown in Figure 4. A typical time 
A
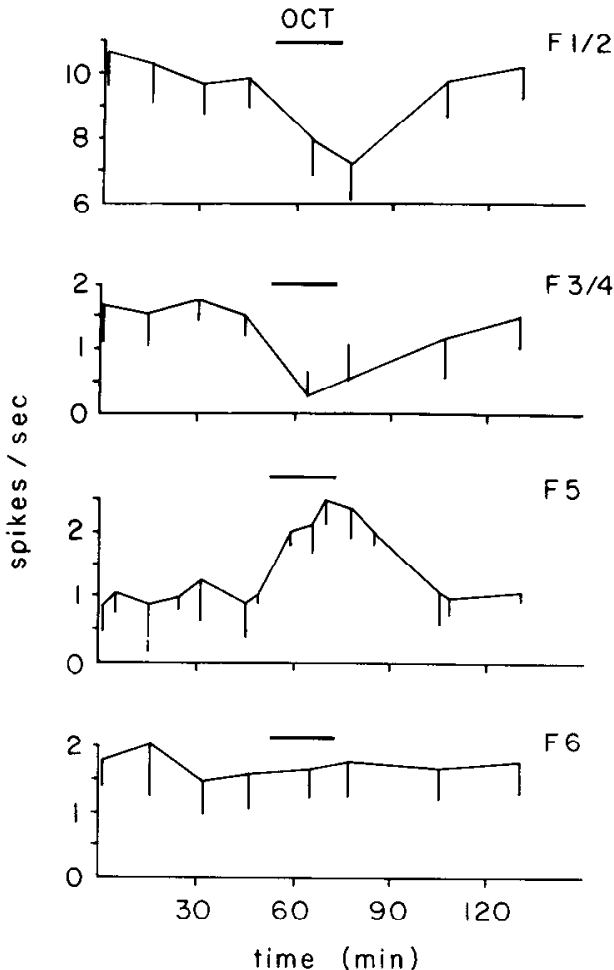

FLEXORS
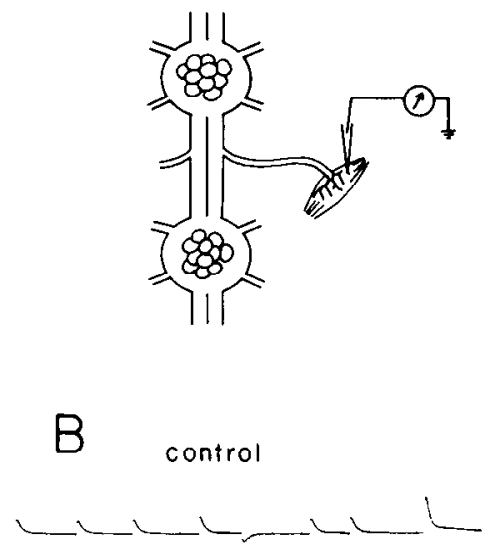

octopamine

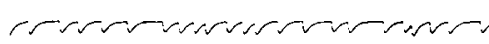

C
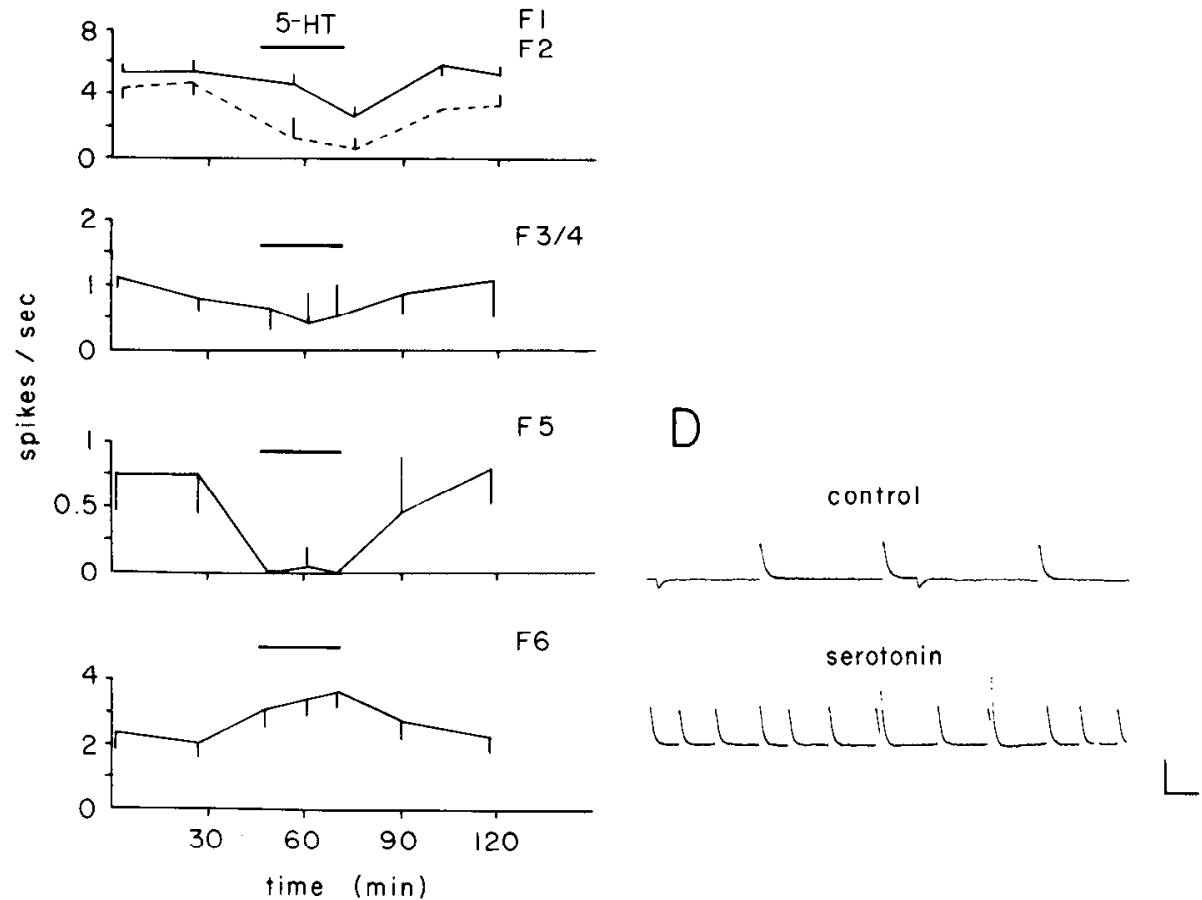

Figure 4. Examples of the effects of octopamine (OCT) and serotonin (5-HT) on motoneurons innervating the superficial flexor muscles. $A$, Effect of octopamine $\left(3 \times 10^{-5} \mathrm{M}\right)$ superfusion on average spike frequency (1 SD shown) in flexor motoneurons F1 to F6. (From Kravitz et al., 1983; used with permission from Elsevier Publications (Cambridge)). $B$, Strong effect of octopamine ( 3 $\times 10^{-5} \mathrm{M}$ ) on motor input to the slow flexor muscle (different experiment than $A$ ). Intracellular recordings from a muscle fiher before and during octopamine superfusion are shown. $C$, Effects of serotonin $\left(3 \times 10^{-5} \mathrm{M}\right)$ on $\mathrm{F} 1$ to $\mathrm{F} 6$ average spike frequency. $D$, Strong effect of serotonin $(3 \times$ $10^{-5} \mathrm{M}$ ) on EJP and IJP frequency in a postural flexor muscle fiber (different experiment than $C$ ). Time markers in $B$ and $D, 1$ sec; amplitude, $2 \mathrm{mV}$. 

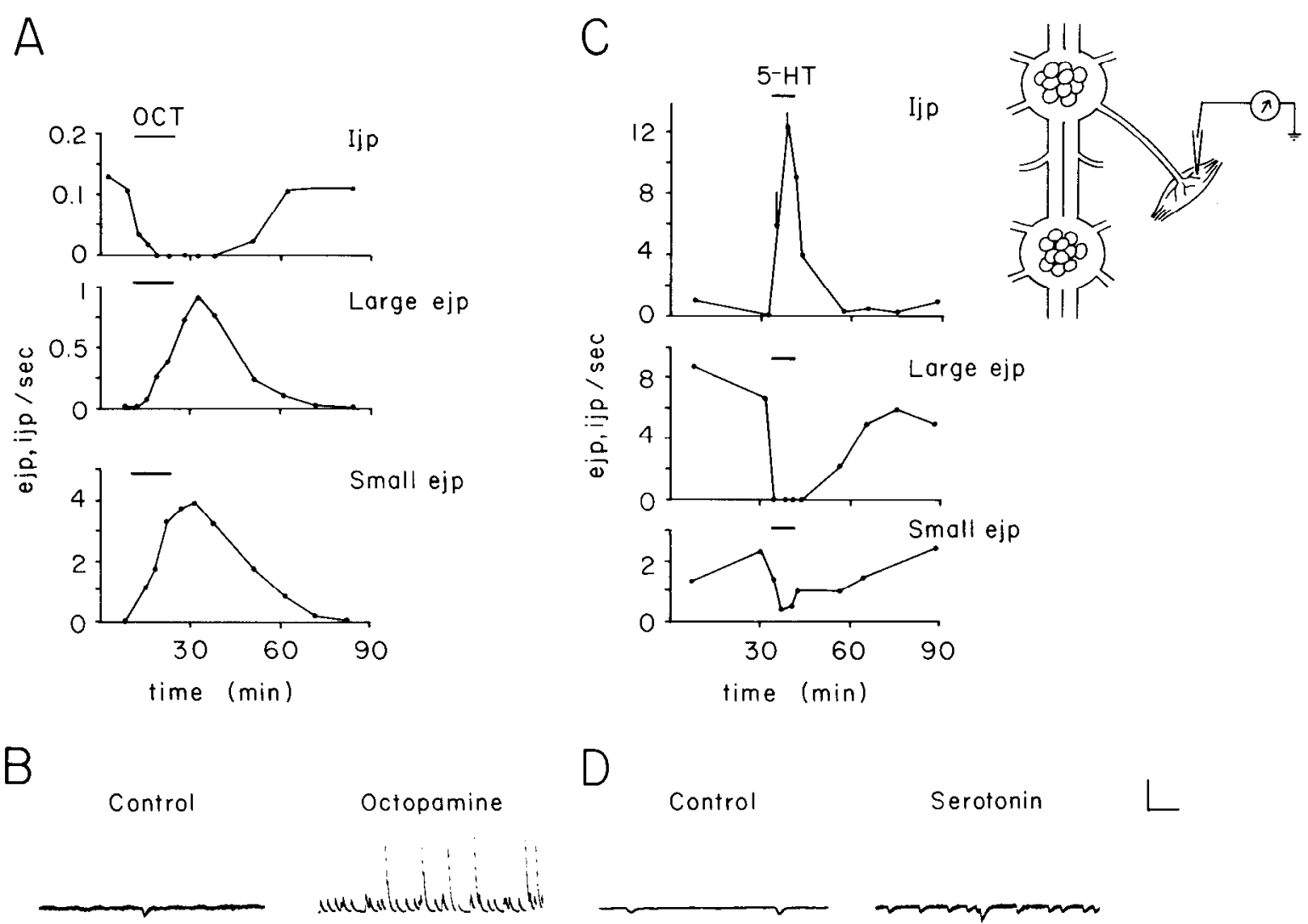

D

Control Serotonin 
$A$
Control

Control

EXT. R.

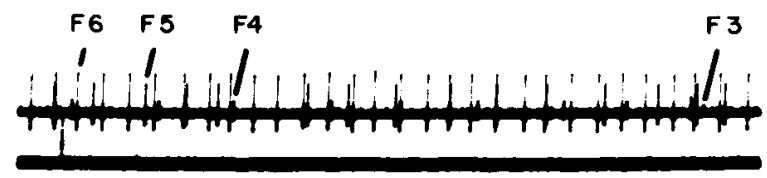

\section{Octopamine}

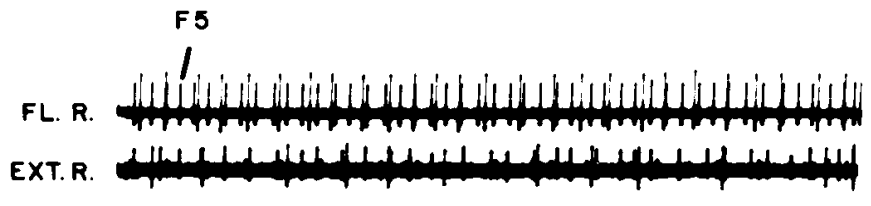

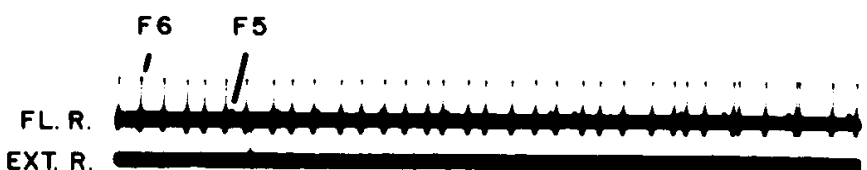

EXT. R.

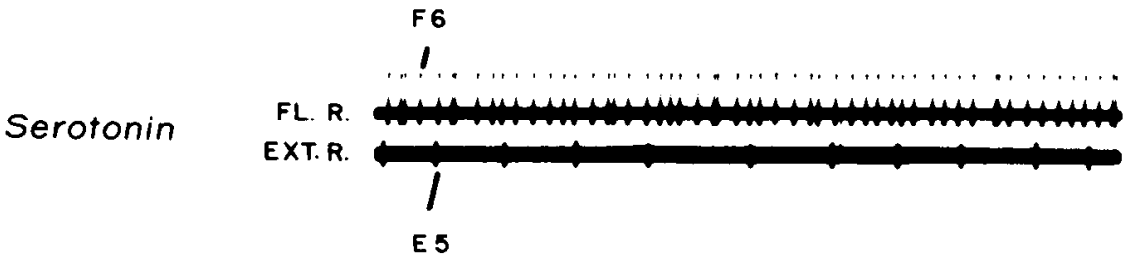

I Sec

Figure 6. Effects of octopamine and serotonin on spike frequency in preparations without attached muscles. Extracellular recordings from the superficial branch of the third root (flexor root, FL. R.) and the whole second root (extensor root, EXT.R.) are shown. The individual postural flexor units F3 to F6 can be distinguished by their amplitudes, as described in the text. The amine-evoked extensor motor activity in the second root is postural: amines do not activate motoneurons to deep (phasic) extensor muscles (see "Materials and Methods"). The extensor inhibitor, E5, was identified by stimulation with a flexion command fiber. $A$, Effect of octopamine. In the control, flexor axons F3 to F6 are identifiable, whereas the extensor root is silent. Octopamine $\left(3 \times 10^{-5} \mathrm{M}\right)$ causes a marked activation of the peripheral flexor inhibitor, F5 (second largest spike in the recording), completely inhibits $\mathrm{F} 3$ and $\mathrm{F} 4$, but has little effect on $\mathrm{F} 6$. It also activates multiple excitatory axons in the extensor root but does not activate the extensor inhibitor, E5. B, Effect of serotonin. In the control, only F6- (large unit) and F5 (small unit) are detectable in the flexor root, whereas the extensor root is silent. Serotonin $\left(3 \times 10^{-5} \mathrm{M}\right)$ excites $\mathrm{F} 6$ and completely inhibits F5 in the flexor root. Simultaneously, it activates E5, the peripheral extensor inhibitor, in the extensor root and does not activate any excitatory motoneurons to the extensor muscle.

with isolated ventral nerve cords (without extensor muscles or exoskeleton) we obtained a clearer picture of the central effects of serotonin (Fig. 6B). In these experiments, spontaneous activity in second roots was very low, and bath application of serotonin activated the peripheral extensor inhibitor, E5, which was identified by activation during stimulation of command fibers for postural flexion isolated from the caudal abdominal nerve cord (Evoy and Kennedy, 1967; R. M. Harris-Warrick, unpublished data). Serotonin did not activate any excitatory extensor units in second roots in the isolated nerve cord preparation, whereas octopamine activated several other units (but not the presumptive E5) in the same experiments (Fig. 6A). At the same time, serotonin silenced the flexor inhibitor, F5, and activated the excitatory flexor motoneuron, F6 (see flexor root (Fl. R.), Fig. 6B). As with octopamine, these experiments show that sensory feedback is not required for the motor patterns generated by serotonin.

\section{Amine effects in an isolated abdominal ganglion}

Octopamine and serotonin activate postural motor patterns in a single isolated abdominal ganglion in the absence of input from other ganglia as well as the periphery. In three experiments, the first abdominal ganglion was isolated, with the postural flexor muscles attached (no sensory axons are found in the superficial third root (Thompson and Page, 1982)). In 
this reduced preparation, bath application of octopamine increased the firing rate of the peripheral inhibitor to flexors, F5, and decreased excitatory input to the flexor muscles. Serotonin superfusion decreased the firing rate of $F 1$ and $F 2$, increased the firing rate of the phasically active F3 and F4 units, and slightly increased the firing of F6. F5 was silent during serotonin superfusion. This pattern was unchanged after cutting the superficial third root to isolate the ganglion from the muscle.

\section{Time course of amine effect on motor patterns}

Although the time course for onset of the effects of serotonin and octopamine were similar, the effects of serotonin were generally more transient than those of octopamine (Figs. 5 and 8). In some preparations, the serotonin effects began to decline in the continued presence of the amine (Fig. 5), and in two experiments this decline was accompanied by an apparent "rebound" activation of an opposite motor pattern (see above and Livingstone et al., 1980). Complete recovery after washout of serotonin took 20 to $30 \mathrm{~min}$. The actions of octopamine were more prolonged: reversal was never observed in the presence of the amine, and, after $3 \times 10^{-5} \mathrm{M}$ octopamine, complete recovery took more than $1 \mathrm{hr}$.

\section{Amine levels in the abdominal nerve cord}

Serotonin and octopamine could exert their central effects on motor output either as neurohormones circulating in the hemolymph, or as neurotransmitters or neuromodulators released from nerve terminals within the ganglia. In support of a direct central action of the amines, we have found octopamine and serotonin in abdominal ganglia. Evans et al. (1976) and Livingstone et al. (1981) detected octopamine in the abdominal nerve cord using a radioenzymatic assay; however, serotonin was not found with the assay used. We have confirmed that octopamine is present in the nerve cord, in the first and second abdominal ganglia (1.65 \pm 0.25 (SD) $\mathrm{pmol} / \mathrm{mg}$ wet weight, $n=$ 5). In addition, using a sensitive HPLC assay with electrochemical detection, we have been able to measure low concentrations of serotonin in abdominal ganglia $(90 \pm 70$ (SD) $\mathrm{fmol} / \mathrm{mg}$ wet weight, $n=5$ ). Thus, octopamine and serotonin are available for release from nerve terminals in abdominal ganglia.
Amine effects on identified postural motoneurons in abdominal ganglia

Our next step in trying to understand the changes in central motor patterns generated by serotonin and octopamine was to record intracellularly from the somata of two easily identified motoneurons that innervate the postural flexor and extensor muscles: F5, the peripheral inhibitor to slow flexor muscles (called $\mathrm{I} 1$ by Otsuka et al., 1967) and M15, which is one of the five excitatory motoneurons innervating the slow extensor muscles (Barker et al., 1972). When activated, both of these neurons contribute to postural extension and thus should be activated by octopamine and inhibited by serotonin. The somata of these neurons are electrically passive and receive no direct synaptic input. Synaptic potentials and action potentials arise from distant sites in the neuropil; therefore our recordings of these events from the cell body are distorted both in size and time course by passive propagation from their sites of origin. Despite these limitations, however, it seemed reasonable to begin the analysis of the actions of serotonin and octopamine at this point. In several other invertebrate and vertebrate preparations, the cell bodies of neurons are responsive to neuromodulators (Gerschenfeld and Paupardin-Tritsch, 1974a, b; Deterre et al., 1981; Dunlap and Fischbach, 1981; Hartzell, 1981; Klein et al., 1982; Benson and Levitan, 1983) even though the sites of synaptic modulation are not located on the somata.

Resting potential. The resting potentials of the cell bodies of F5 and M15 were only slightly affected by bath application of either serotonin or octopamine. Octopamine sometimes produced a 1 to $2 \mathrm{mV}$ depolarization and serotonin a 0.5 to $2 \mathrm{mV}$ hyperpolarization, but neither effect was always observed. We cannot tell whether there are significant changes in membrane potential in the neuropil.

Input resistance. The input resistance was calculated from the slope of the $\mathrm{I} / \mathrm{V}$ relationship determined in the somata. The I/V plot is approximately linear over a $20 \mathrm{mV}$ range on either side of the resting potential ( $R_{i n}=0.5$ to $\left.2 \times 10^{6} \mathrm{ohms}\right)$. Administration of serotonin or octopamine did not change the I/V slope significantly (Fig. 7) under conditions where cell excitability was dramatically altered (see below). We have also measured $\mathrm{I} / \mathrm{V}$ relationships under conditions of blockade of potassium channels by $7.5 \mathrm{mM} 4$-aminopyridine and $75 \mathrm{~mm}$ tetraethylammonium (TEA), sodium channels by $2 \times 10^{-7} \mathrm{gm} /$ $\mathrm{ml}$ of tetrodotoxin, or calcium channels by $40 \mathrm{mM}$ cobalt ion.

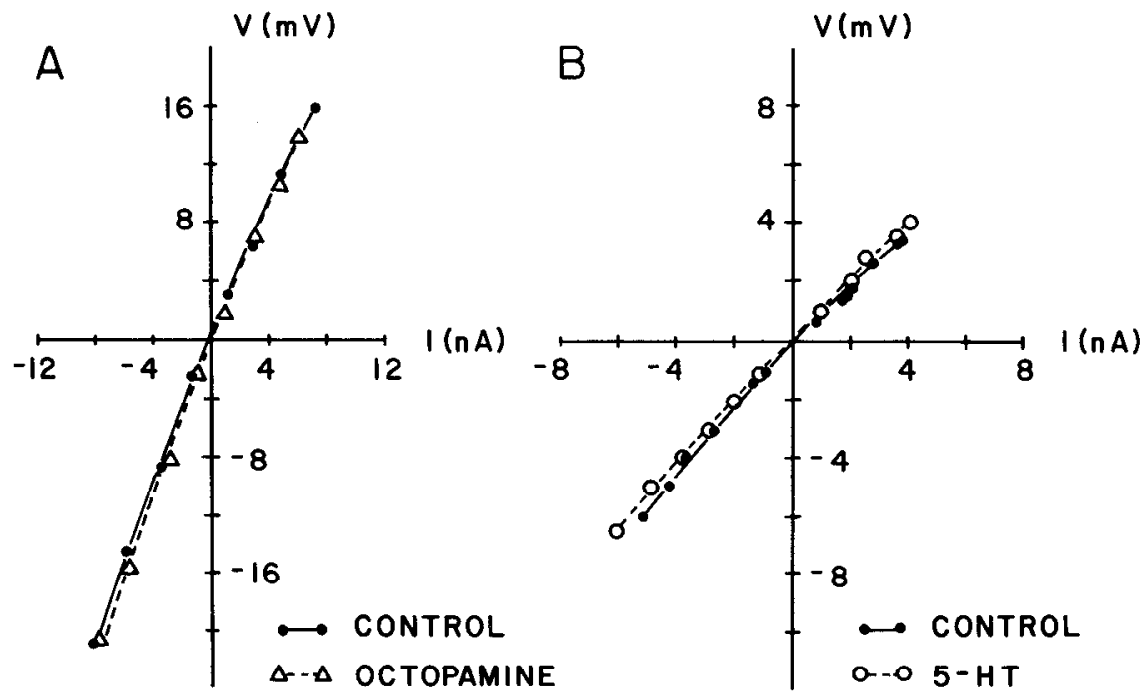

Figure 7. I/V curves recorded from the soma of the flexor inhibitor, F5. The soma is electrically inexcitable and yields linear $\mathrm{I} / \mathrm{V}$ curves. Octopamine $\left(A, 3 \times 10^{-5} \mathrm{M}\right)$ and serotonin $\left(B, 3 \times 10^{-5} \mathrm{M}\right)$ do not affect the $\mathrm{I} / \mathrm{V}$ relationship. 
Although these treatments altered the I/V relationship, neither serotonin nor octopamine caused any further change in input resistance.

Excitability. Octopamine superfusion dramatically increased the excitability of these cells. This was measured as a reduction in the depolarization of the cell body required to initiate an action potential at the distal spike initiation zone (i.e., a reduction in the "apparent spike threshold"). Increased excitability was observed in both F5 (Fig. 8A) and M15 (data not shown). The effect was particularly obvious in cells that were silent at rest and had higher initial "apparent spike thresholds." This effect had the same slow time course as the other parameters described above. M15 was silent under control conditions, and despite a significant reduction in the "apparent spike threshold" it remained silent during octopamine administration. Thus, octopamine has an excitatory effect on motoneuron M15 that was not detected by the extracellular recordings of spike frequency used in the earlier experiments.

Serotonin superfusion reduced the excitability of these cells, raising the amount of depolarization required to initiate action potentials in both F5 (Fig. 8B) and M15 (data not shown). The onset of this effect was rapid, and recovery after washout was faster than with octopamine, usually taking 20 to $30 \mathrm{~min}$.

Amine effects on excitability were not seen in all neurons in an abdominal ganglion. As a control, we measured the effects of octopamine and serotonin on $\mathrm{I} 2$, a large inhibitory neuron innervating the fast flexor muscles. This cell is not normally involved in the maintenance of posture and does not fire action potentials upon treatment with either amine. With intracellular recording, the "apparent spike threshold" was high and was not altered by bath application of either serotonin or octopamine (Fig. 8, $C$ and $D$ ).

\section{Mechanism of amine effect on motoneuron excitability}

The change in excitability caused by octopamine and serotonin could be due to either direct or indirect amine effects on

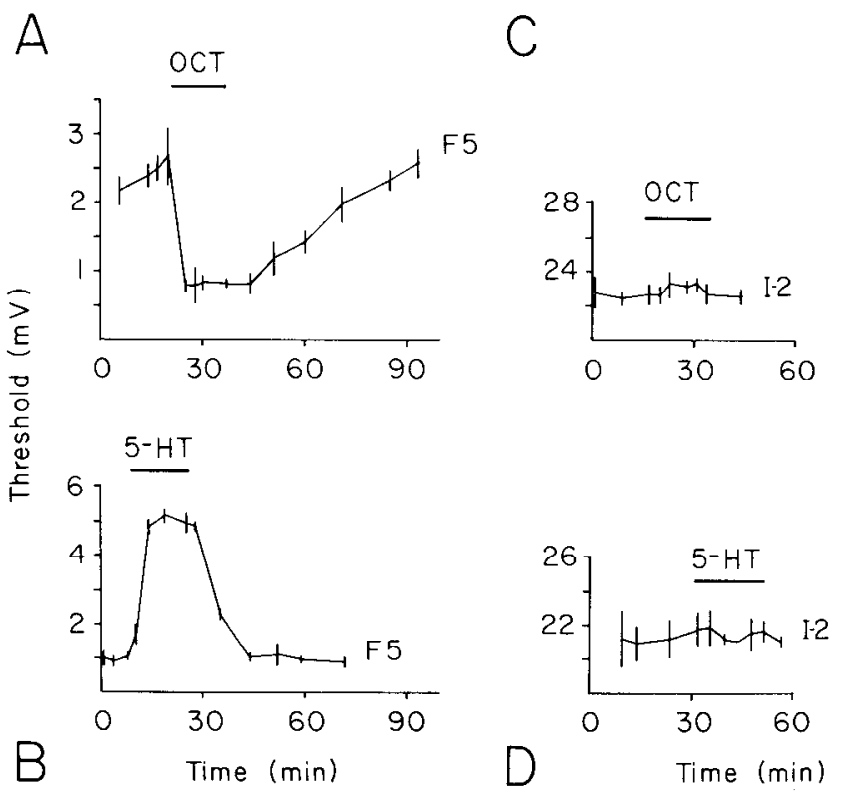

Figure 8. Effects of octopamine (OCT) and serotonin (5-HT) on apparent threshold for action potential generation in postural flexor inhibitor, F5 ( $A$ and $B$ ) and the phasic fast flexor inhibitor, $\mathrm{I} 2(C$ and $D$ ). Current was injected in the cell body with one electrode. The threshold depolarization that reproducibly elicited an action potential in the neuropil was recorded with a second electrode. Amines $\left(3 \times 10^{-5}\right.$ M) were superfused over the preparation for 15 to $20 \mathrm{~min}$, as shown by the bars. the motoneurons. Amines could act directly on motoneurons to: $(a)$ alter the threshold for action potential generation at the spike initiation zone in a cell, or (2) alter the passive electrical properties of the membrane in the neuropil (e.g., increase the membrane resistance) and thus change the effectiveness of synaptic input to the cell. Alternatively, the amines could act indirectly by modifying the activity of unidentified neurons providing synaptic input to the motoneurons. Enhanced or diminished synaptic input could alter the membrane conductance or membrane potential in the vicinity of the spike initiation zone, thereby changing the amount of additional depolarization from the cell body needed to initiate an action potential. Changes in membrane potential or conductance close to the spike initiation zones might be difficult to detect in recordings from cell bodies due to the long electrotonic distance separating the two sites. In addition, some combination of direct and indirect mechanisms is possible. The following experiments suggest that the amines affect these two motoneuron types indirectly by changing the frequency of firing of particular synaptic inputs to the cells.

Blockade by low calcium, high cobalt saline. If serotonin and octopamine indirectly affect motoneuron excitability by exciting or inhibiting interneurons providing synaptic input to the motoneurons, amine effects should disappear during blockade of synaptic activity in the abdominal ganglia. Difficulty in changing the ionic composition of the saline in crustacean ganglia by bath superfusion has been reported (see Footnote 18 in Zucker et al., 1971; Brown and Sherwood, 1981). In our experiments, we found it necessary to replace the normal 28 $\mathrm{mM} \mathrm{CaCl}{ }_{2}$ in our lobster saline with 20 to $40 \mathrm{~mm} \mathrm{CoCl} \mathrm{Cl}_{2}$ to completely block synaptic input to these motoneurons. The disappearance of synaptic activity was monitored by measuring the amplitude of the dual EPSP-IPSP generated in M15 by stimulation of the stretch receptor organ (Barker et al., 1972). During washing of cobalt, neurons initially were activated and fired action potentials at high frequencies. This was accompanied by a 4 to $6 \mathrm{mV}$ depolarization. Eventually, the cells became silent and, within 20 to $30 \mathrm{~min}$, all detectable synaptic activity ceased. In the absence of synaptic input, the threshold for action potential generation by current injection into the soma was significantly elevated. Octopamine and serotonin (3 $\left.\times 10^{-5} \mathrm{M}\right)$ had no detectable effect on the "apparent spike threshold" when synaptic activity was abolished. (Fig. 9). After washout of the amines and return to normal ionic conditions for 30 to $60 \mathrm{~min}$, both amines again affected threshold in the usual way (data not shown).

Amines affect spontaneous EPSP frequency. At rest, small EPSPs and IPSPs were visible in soma recordings from F5 (Fig. 10B). Bath application of octopamine $\left(3 \times 10^{-5} \mathrm{M}\right)$ caused a significant increase in EPSP frequency in F5 similar in time course to increases in spontaneous action potential frequency (Fig. 10). This increase in EPSP frequency varied somewhat from preparation to preparation: although increases of up to $300 \%$ have been observed, the average increase was 50 to $100 \%$. In contrast, IPSP frequency in F5 was not affected by bathapplied octopamine. Similar results were obtained in recordings from M15 (data not shown).

These data suggest that octopamine either increases excitatory synaptic input to these motoneurons or alters the membrane properties of the motoneurons to make the EPSPs larger and more likely to be detected in the cell body. The following results support the first hypothesis. (1) Octopamine did not affect the input resistance recorded in the soma (see above). This argues against but does not preclude possible changes in input resistance at remote sites in the neuropil. (2) Octopamine did not change the amplitude or the time course of a dual EPSP-IPSP evoked in M15 by stimulation of the stretch receptor organ (Barker et al., 1972; Fig. 11A). (3) Octopamine 


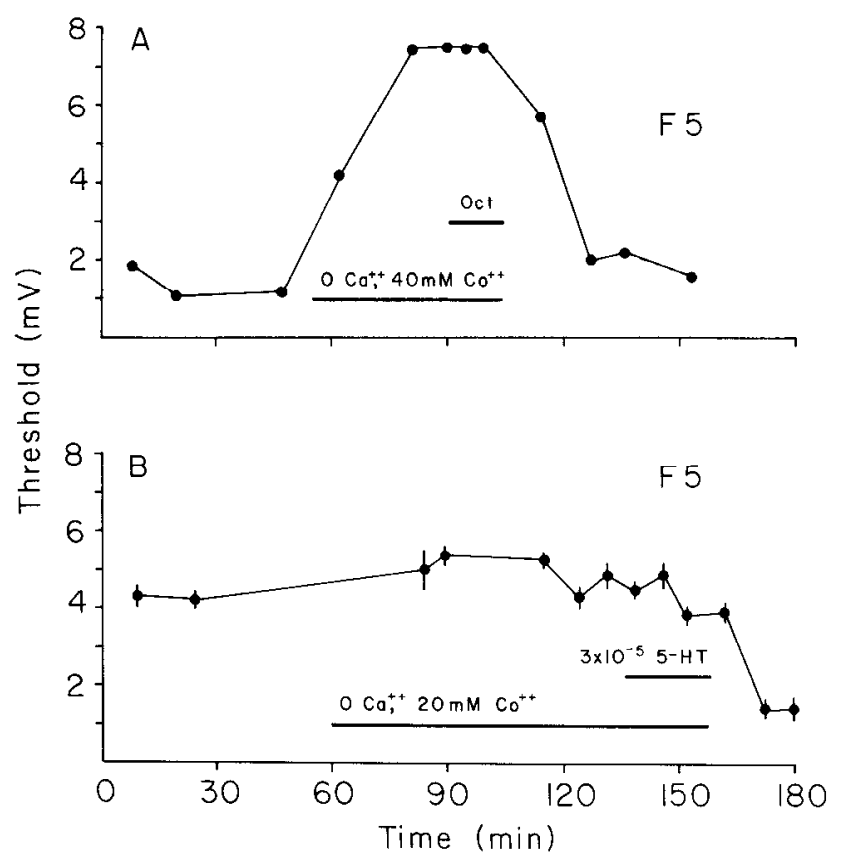

Figure 9 . Blockade by cobalt ion of aminergic modulation of apparent spike threshold in F5. The apparent threshold for action potential generation was measured as described in the legend to Figure 8. At the times indicated, the normal saline was replaced by saline with no calcium and $40 \mathrm{~mm}(A)$ or $20 \mathrm{~mm}(B) \mathrm{CoCl}_{2}$. Under these conditions, synaptic activity ceased in 30 to $60 \mathrm{~min}$. Octopamine $(A)$ and serotonin $(B)$ (both at $3 \times 10^{-5} \mathrm{M}$ ) had no effect on spike threshold under these conditions.

had no effect on the amplitude or time course of the retrograde action potential in F5 (Fig. 11B) and M15 (data not shown), either under normal ionic conditions or during blockade of potassium conductance by $7.5 \mathrm{mM} 4$-aminopyridine and $75 \mathrm{mM}$ TEA. Spontaneous action potentials, which are larger than retrograde action potentials, also were unaffected by octopamine. (4) The frequency and amplitude of spontaneous IPSPs in F5 and M15 do not change during octopamine superfusion. (5) Measurements were made of the amplitudes of spontaneous EPSPs in F5 before and during bath application of amines. Under control conditions (Fig. 12A), the EPSP amplutude was normally distributed with a mean amplitude of $0.11 \pm 0.04$ (SD) $\mathrm{mV}$ : few units were greater than $0.2 \mathrm{mV}$ in amplitude. During bath application of octopamine, the average amplitude of EPSPs was significantly increased. However, a histogram of EPSP amplitudes (Fig. 12B) showed that a normally distributed group of EPSPs with a mean amplitude of $0.11 \mathrm{mV}$ still was present. In addition, a new class of larger EPSPs appeared (mean size, $0.2 \mathrm{mV}$ ), and EPSPs with amplitudes of $0.3 \mathrm{mV}$ or greater were observed. The simplest explanations of these data are that new synaptic inputs that are either larger or closer to the soma were activated by octopamine, or that octopamine acted presynaptically to increase the quantal content of selected synaptic potentials.

Serotonin had lesser effects on the motoneurons. In most experiments, a small (10 to 50\%) decrease in EPSP frequency was observed (Fig. 10C); there was no significant alteration in the distribution of EPSP amplitudes recorded in F5 during serotonin superfusion. As noted above, serotonin did not affect the input resistance of the two motoneurons in soma recordings. Serotonin did not detectably affect the resistance at distal sites in the neuropil, as estimated indirectly by measurements of the EPSP-IPSP in M15 evoked by stimulation of the stretch receptor organ and the amplitudes and shapes of retrograde or spontaneous action potentials. Finally, serotonin had no effect on the amplitude or frequency of spontaneous IPSPs.

\section{Discussion}

In this paper, we have studied the neural basis for the generation of opposing postures by octopamine and serotonin in the lobster. We suspect that amines are normally involved in the generation or modulation of posture in intact animals, but thus far we have no direct evidence to support this suggestion. Instead, we observed that high concentrations $\left(10^{-6}\right.$ to $10^{-5} \mathrm{M}$ ) of amines generate postures in intact animals and activate coordinated patterns of postural motoneuron activity in vitro. The requirement for high concentrations suggests that the amines do not normally affect posture as circulating neurohormones: amines circulate in the hemolymph at concentrations of $10^{-9}$ to $10^{-8} \mathrm{M}$ (Livingstone et al., 1981). Even if all of the serotonin or octopamine in a lobster were simultaneously released into the hemolymph, the concentrations would not reach the levels required to change posture in intact animals. We have shown, however, that endogenous serotonin and octopamine are present in abdominal ganglia and connectives. In addition, Beltz and Kravitz (1983) have used immunohistochemical methods to detect serotonin-like immunoreactivity in neurons and neuropil regions throughout the ventral nerve cord. A reproducible number of presumed serotonin-containing cell bodies and elaborate arborizations with punctate processes are found in individual abdominal ganglia. We believe that amines released from nerve terminals in the central ganglia could achieve the local high concentrations required at sensitive sites to direct the activation of central motor programs for flexion and extension. In the experiments we have carried out to date, the amines are delivered by a nondirected method (injection or bath superfusion). Under these conditions, any neurons that have aminergic receptors will be affected, thereby complicating the analysis of specific synaptic effects of amines on components of the postural motor systems. Despite this, our results for octopamine and, to a lesser extent, serotonin show patterns of neuronal activation that allow us to offer partial explanations for the postures evoked by in vivo injections.

Peripheral actions of the amines. The postures of an amineinjected animal are not likely to result from direct, hormonal activation of selected postural muscles by octopamine or serotonin. Both amines affect neuromuscular transmission, but in three pairs of flexor-extensor muscles we found no evidence for selective activation of either category of muscle by either amine (Figs. 1 to 3, Table I). As shown in Table I, the pattern of neuromuscular modulation varied between different muscle pairs, but the symmetrical activation by an amine of flexors and extensors within each muscle pair was always seen. Thus, both amines caused prolonged contractures of the opener and closer muscles of the walking leg, whereas no amine-induced contractures were observed in the flexor and extensor muscle pairs in the abdomen or in the meropodite of the walking leg. As described above, serotonin affects the amplitude of electrically induced muscle contractions in the abdominal extensors, suggesting a direct effect of the amine on muscle contractility, but this effect is not revealed as a change in the resting tension in this muscle. Serotonin increased the amplitudes of junctional potentials in all muscles tested, whereas under normal experimental conditions, octopamine enhanced the amplitude of junctional potentials only in the flexor and extensor pair from the abdomen. The EJPs and IJPs recorded from walking leg muscles were not increased by octopamine. The overall result was that the two amines act in concert to enhance muscle responses to motoneuronal activation. With respect to posture, however, this enhancement is totally nonselective. If peripheral actions of the amines cannot account for the postures observed upon 


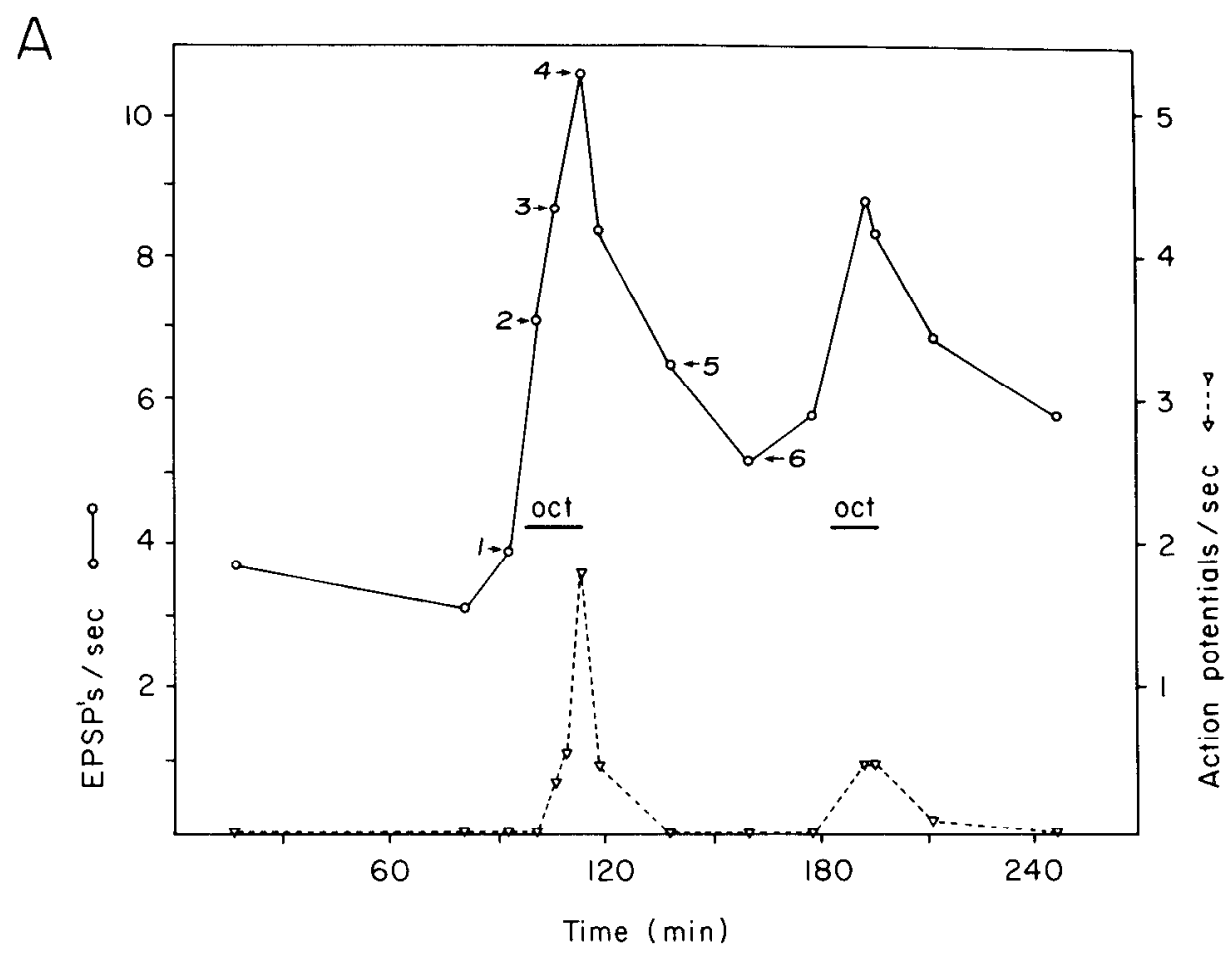

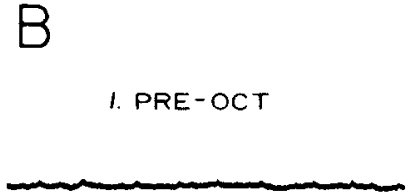

2. OCT (4')

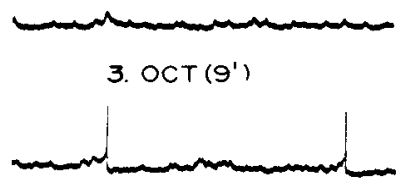

C

PRE - 5 HT

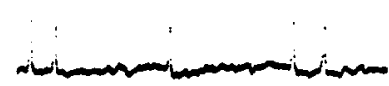

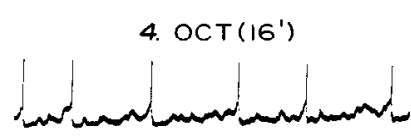

5. WASH (25')

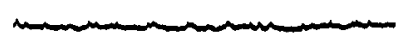

6. WASH (47')

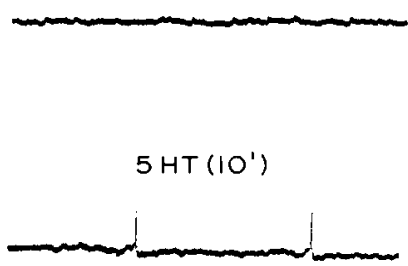

Figure 10. Effect of octopamine $(A$ and $B)$ and serotonin $(C)$ on spontaneous EPSP and spike frequency in the flexor inhibitor, F5. Typical intracellular recordings are shown in $B$, at the times denoted by the numbers in $A, A$, Left ordinate: EPSPs per second; right ordinate: action potentials per second. $B$ and $C$, Time marker, $1 \mathrm{sec}$; amplitude, $1 \mathrm{mV}$.

amine injection in vivo, then central mechanisms must be involved.

Central actions of the amines. To study aminergic activation of patterns of motoneuron activity leading to flexion or extension, we analyzed their effects on the isolated abdominal nerve cord. The spontaneous rate of firing of motoneurons in the isolated nerve cord is reduced compared to that seen in the intact animal. This probably results from the loss of input from other ganglia and the loss of sensory feedback. Because of the reduced activity, the effects of amines on firing patterns of motoneurons were less dramatic than those observed behaviorally. However, octopamine activated a coordinated motor program in the isolated preparation that should result in postural extension. Serotonin had more mixed effects on motoneuron activity, but it clearly supported a qualitative change toward a more flexed posture. 

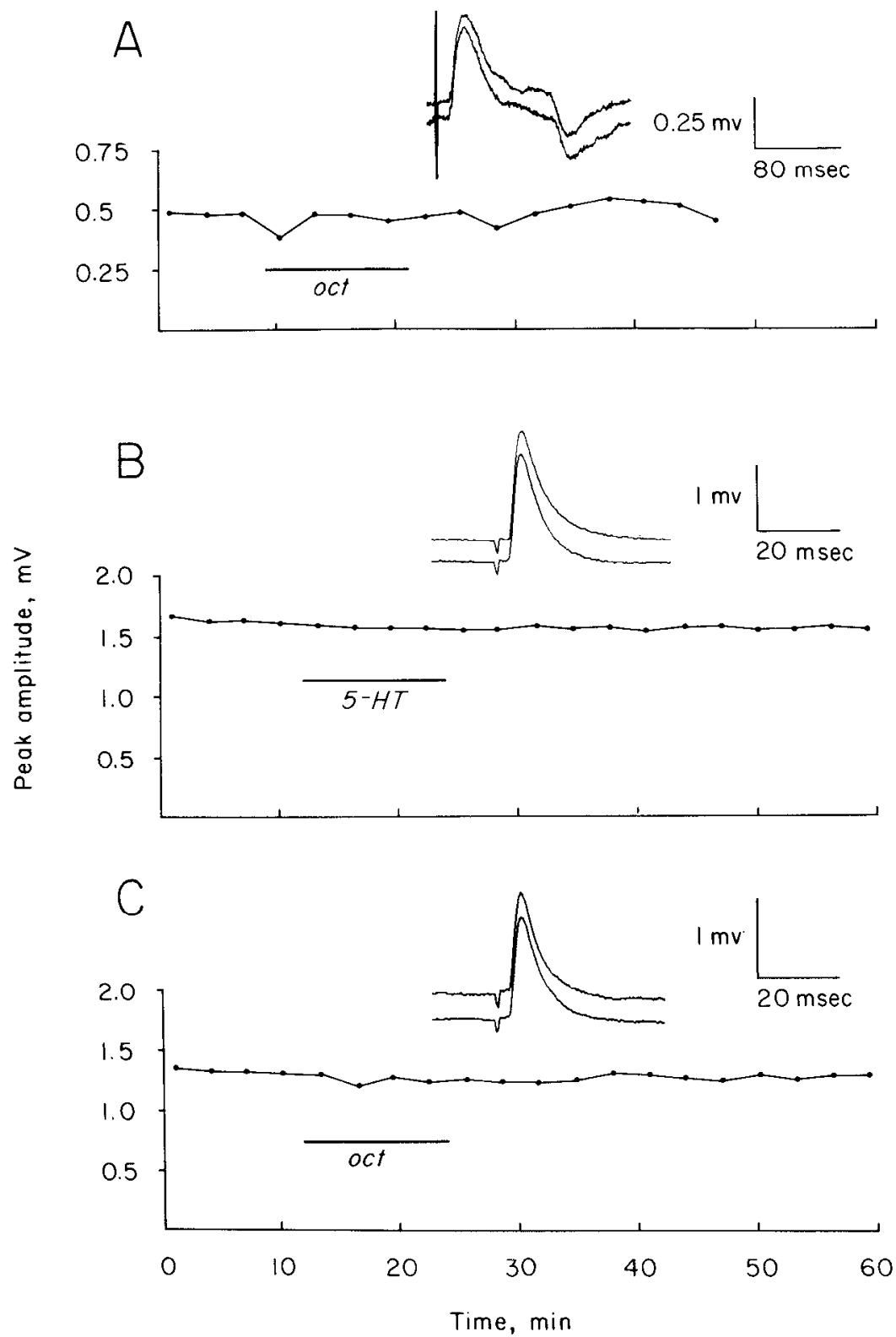

Figure 11. A, Absence of octopamine effect on evoked EPSP and IPSP in M15, elicited by stimulation of the stretch receptor organ. The inset shows records signalaveraged by a PDP 11/03 computer before (bottom) and during (top) $3 \times 10^{-5} \mathrm{M}$ octopamine. $B$, Absence of serotonin effect on retrograde action potential recorded in F5. The action potential was elicited by stimulation of the superficial third root and was averaged by the PDP 11/03 microcomputer. Insets, Records before (top) and during (bottom) serotonin. $C$, Absence of octopamine effect on retrograde action potential in F5, elicited as in $B$.

In vitro recordings from the abdominal nerve cord with attached postural muscles showed that octopamine activates a coordinated change in motoneuron activity leading to postural extension: it activates excitatory motoneurons and inhibits the peripheral inhibitory neuron innervating postural extensor muscles; simultaneously, octopamine activates the peripheral inhibitory neuron and decreases the activity of the excitatory motoneurons innervating the postural flexor muscles. These results could also be observed in a single isolated abdominal ganglion, in the absence of sensory feedback or input from other central ganglia. There were some differences in the strength of the octopamine effect on different postural motoneurons. For example, F3 and F4 (the phasically active motoneurons causing large EJPs in postural flexors) were strongly inhibited, whereas F6 (causing small "EJPs in postural flexors) was not reproducibly affected. Although this variability in responsiveness may be real, several other explanations are also possible. For example, since we added octopamine by bath application, amine-sensitive neurons that are not normally involved in the generation of posture could be activated and affect these motoneurons. These differences may also arise from differential penetration of bath-applied amine to active sites in the neuropil.

We have performed a more detailed analysis, by using intracellular recording, of the effects of octopamine on two postural motoneurons, F5 (the inhibitory neuron to postural flexors) and M15 (one of the excitatory motoneurons to postural extensors). From the analysis of motor patterns, we expected octop- 

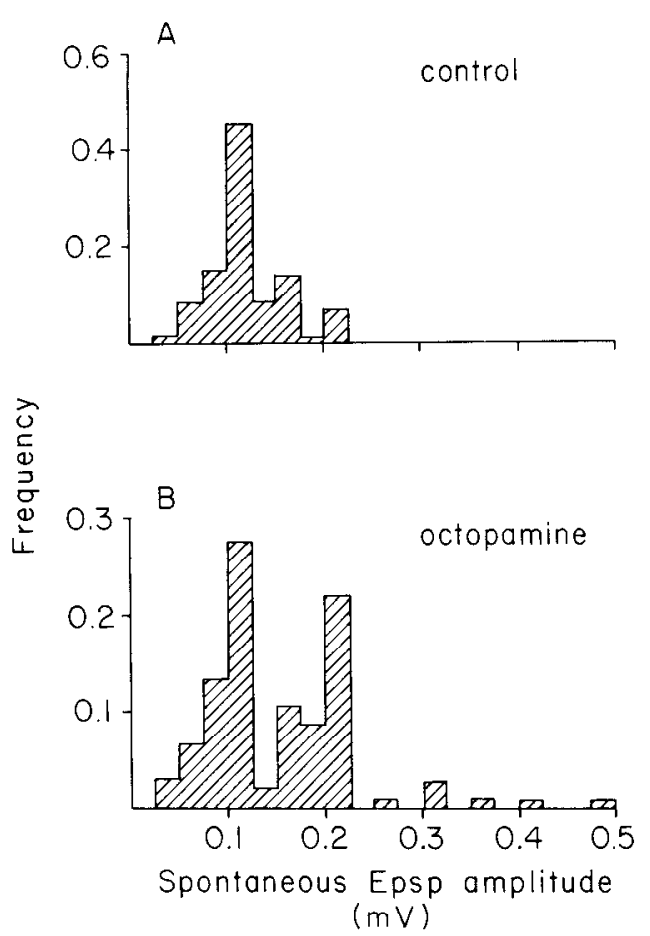

Figure 12. Histogram of spontaneous EPSP amplitude in F5 before $(A)$ and during $(B)$ superfusion with $3 \times 10^{-5} \mathrm{M}$ octopamine. Abcissa, Peak amplitude of EPSP, in $25-\mu \mathrm{V}$ bins. Ordinate, Fraction of total EPSPs with that amplitude.

amine to activate both of these cells. F5 shows spontaneous action potentials whose frequency is increased by octopamine; $\mathrm{M} 15$, on the other hand, shows no spontaneous activity either before or after octopamine. Octopamine increases the excitability of both M15 and F5, however, as seen by a reduction in the depolarization of the soma required for generation of action potentials. The mechanism by which octopamine affects this reduction in the apparent action potential threshold appears to be, at least in part, by changing the firing of neurons that synapse with the motoneurons at or near their action potential initiation zone. For example, we found that EPSP frequencies in F5 and M15 increase significantly during bath application of octopamine (Fig. 10). The analysis of EPSP amplitudes suggested that octopamine activates a previously silent population of large-amplitude excitatory inputs to these motoneurons (Fig. 12). In the same experiments, we did not detect any changes in IPSP frequency or in the amplitudes of selected evoked EPSPs, IPSPs, or action potentials. In addition, cobalt completely blocked the reduction in threshold by octopamine (Fig. 9), presumably by preventing the release of transmitter from the terminals in synaptic contact with motoneurons.

Although these experiments suggest that octopamine acts on neurons presynaptic to motoneurons rather than on the motoneurons themselves, alternative explanations are possible. For example, octopamine could selectively increase the input resistance of a selected portion of the dendritic arborization in a motoneuron, thus increasing the amplitude of only one population of synaptic inputs to the cell. In addition, cobalt could block an effect of octopamine on a population of calcium channels in the motoneuron membrane that are important in determining the spike initiation threshold (see, for example, Kravitz et al., 1980, for such an action of amines on spike initiation in lobster exoskeletal muscles). We searched for changes in the membrane properties (resting potential, input resistance) of motoneurons in recordings from the somata, but we were unable to detect any. In addition, in looking for possible effects on membrane resistance at a distance from the soma in the neuropil, we examined, but found no effect of, octopamine on the amplitude of time course of evoked EPSPs, IPSPs, or retrograde action potentials. Nor did we find any changes in calcium conductance by studying I/ $\mathrm{V}$ relationships in cell somata when potassium or sodium channels were blocked with 4aminopyridine, TEA or tetrodotoxin. Finally, we failed to find octopamine-induced changes in the calcium component of the retrograde action potential after blocking potassium conductance with 4-aminopyridine and TEA. This approach was used by Klein et al. (1980) in similar studies with Aplysia neurons to demonstrate direct and indirect changes in calcium conductance that underly short- and long-term changes in synaptic effectiveness during behavioral habituation and sensitization. Thus, while we cannot rule out the possibility that octopamine has a direct effect on motoneurons, we have not yet been able to measure such an effect.

The central effects of serotonin were varied, but elements of the central generation of a motor pattern leading to flexion were present. A clear pattern was seen with the peripheral inhibitory neurons: serotonin inhibits F5 (the inhibitory neuron to postural flexor muscles) and activates E5 (the inhibitory neuron to postural extensors). These effects contribute to the flexed posture observed in vivo. However, no clear pattern of activation of excitatory motoneurons was seen. Of the five flexor motoneurons, only $\mathrm{F} 6$ was consistently activated, whereas the small, tonically active $F 1$ and F2 units were consistently inhibited by serotonin. Contrary to expectations from the posture, serotonin frequently activated excitatory units producing large EJPs in the postural extensor muscles.

One possible explanation for the lack of specificity in the action of serotonin on postural motoneuron activity is the nondirected method of administration of the amine by bath application. As mentioned above, this should activate all serotonin-responsive neurons, losing the specificity that the patterns of connectivity preserve. Another possible source of confusion in our results is that the preparations with attached postural extensor muscles included peripheral sensory input from the exoskeleton and stretch receptor organ. We do not know whether serotonin has any effect on the excitability of these elements. However, activation of peripheral sensory neurons does alter the activity of the postural motoneurons. Fields (1966) has shown that activation of stretch receptor organs in the crayfish abdomen stimulates at least one excitatory motoneuron to slow extensor muscles. In addition, in the crayfish, the modulation of postural motoneurons by sensory input from receptors in the exoskeleton has been documented by Kuwada and Wine (1979). In experiments in which we cut the second roots to eliminate sensory input, a clearer pattern of motoneuron activity was seen: serotonin activated a single large extensor axon that was identified in some experiments as the peripheral extensor inhibitor E5: excitatory motoneurons to extensor muscles were not activated (Fig. 6B).

In contrast to the variable results on motor patterns, our intracellular studies of the effects of serotonin on motoneurons F5 and M15 were quite reproducible. In contrast to octopamine, serotonin always raised the threshold depolarization required for action potential generation, indicating a reduction in neuronal excitability. Like octopamine, this effect was inhibited by cobalt, suggesting that serotonin acts on neurons providing synaptic input to motoneurons rather than directly on the motoneurons. Using similar experimental protocols, as in the studies with octopamine, we were unable to detect any effect of serotonin on the membrane parameters of the motoneurons. However, serotonin caused only a small reduction in EPSP frequency in the motoneurons. Our evidence for a premotoneuron mechanism for serotonin, therefore, remains incomplete. The recent detection of presumptive serotonin-containing neu- 
rons with characteristic branching patterns in lobster central ganglia (Beltz and Kravitz, 1983) should make it possible to identify and stimulate these cells selectively while recording from identified motoneurons and thereby study the effects of endogenously released serotonin on postural motor output. Such experiments should help to clarify the presently complicated picture of serotonin action.

Amines and command fibers. Kennedy and co-workers (Kennedy et al., 1966, 1967; Evoy and Kennedy, 1967; Bowerman and Larimer, 1974) have studied the neuronal mechanisms that direct abdominal posture in crayfish. These authors showed that single nerve fibers, called command fibers, when stimulated at 30 to $70 \mathrm{~Hz}$, cause animals to assume static postures similar to those we observed upon amine injection in lobsters. Figure 13 gives a schematic outline of the neuronal organization that is thought to generate these tonic postures. The command fibers identified by Kennedy et al. $(1966,1967)$ do not appear to synapse directly upon the postural motoneurons. Instead, it was suggested that they establish synaptic contacts with an unspecified number of coordinating interneurons, called driver interneurons, which interact to organize the motor response. The command fibers act as a switch to activate this organizing circuit. Little is known about the degree of complexity of the driver interneurons, but recent work by Miall and Larimer (1982) in crayfish suggests that both parallel and serial processing of information occurs. Evoy and Kennedy (1967) showed that stimulation of command fibers activates a coordinated pattern of tonic activation and inhibition of multiple postural motoneurons to produce the appropriate posture. For example, an extension command fiber activates tonic firing in some or all of the five excitatory motoneurons and inhibits the peripheral inhibitory motoneuron to extensor muscles. Simultaneously, the peripheral inhibitor to flexors is tonically activated while some or all of the five excitatory motoneurons to the flexors are inhibited. Flexion command fibers cause postural flexion by stimulating an exactly inverse pattern of motoneuron activity. Since the organization of the driver interneuron circuit is not known, the degree of feedback within this apparently hierarchical organization is not known. It is, however, likely tht such feedback exists, and it is noted by the dashed lines in Figure 13. Similar command fibers have been observed in lobsters by Thompson and Page (1982) and ourselves (R. M. Harris-Warrick, unpublished observation). In addition to the command fibers described above, Thompson and Page (1982) observed another category of command fiber (called type 1), which differed in not being symmetrical in its activation and inhibition of the postural motoneurons. Type 1 command fibers also caused direct appearance of EPSPs in a 1:1 fashion in some of the activated motoneurons, suggesting monosynaptic activation by the command fiber. We have also observed type 1 command fibers in lobsters (R. M. Harris-Warrick, unpublished observation).

Our data support the hypothesis that octopamine and, possibly, serotonin interact with the neural networks activated by command fibers. As described above (Figs. 4 and 5), octopamine activates a coordinated pattern of tonic postural motoneuron activity similar to that activated by certain extension command fibers (Evoy and Kennedy, 1967; Thompson and Page, 1982). That is, both octopamine and extension command fibers tonically activate postural extensor muscles by simultaneously activating some or all of the excitatory extensor motoneurons and inhibiting the peripheral inhibitory extensor motoneuron; at the same time, octopamine and extension command fibers tonically inhibit flexor muscle activity by activating the peripheral inhibitory flexor motoneuron and inhibiting some or all of the excitatory flexor motoneurons. Octopamine could interact at several points in a command fiber network (Fig. 13): it could be the neurotransmitter of an extension command fiber or a required driver interneuron in the network that coordinates motor ouput for extension; alternatively, octopamine could modulate the activity of one or more interneurons in the pathway between command fiber and motoneurons. A further analysis of the effects of octopamine on the postural motor system should enhance our understanding of the organization of the system. Serotonin has much more mixed effects than octopamine, but in several respects the opposing actions on

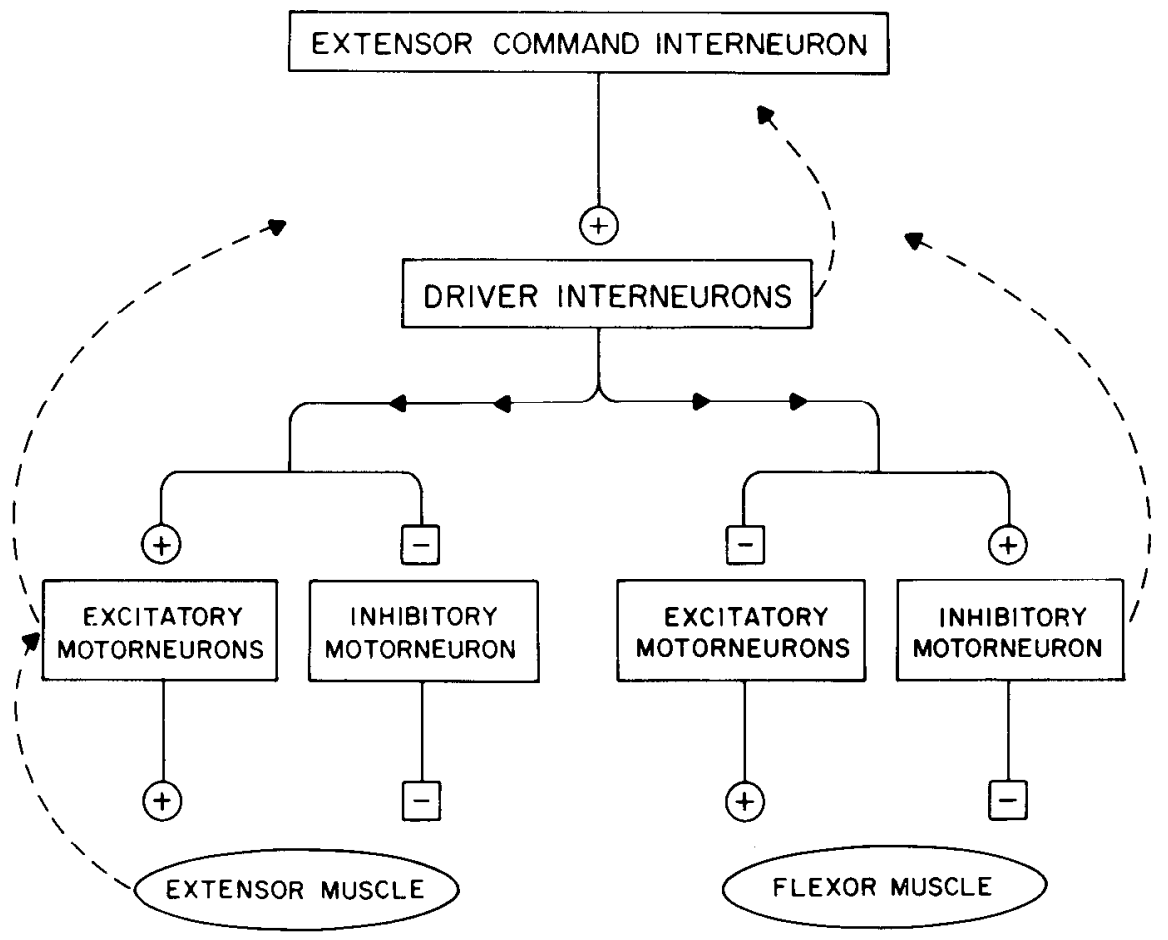

Figure 13. Model of the action of an extensor command fiber. See "Discussion" for details. 
flexor and extensor motoneurons seen upon stimulation of flexor command fibers are observed. Thus, serotonin may modulate the activity of selected neurons in these behavioral circuits.

In summary, our work shows that monoamines act to modulate motor activity in lobsters at two independent levels. First, they act as peripheral neurohormones, released from neurons into the hemolymph, where, at very low concentrations, they activate peripheral neuromuscular preparations. Octopamine and serotonin enhance the motor response in some muscles with no postural specificity coded peripherally: any motor command that reaches an amine-responsive muscle elicits a greater response in the presence of the amine. Second, serotonin and octopamine act in the ventral nerve cord of the lobster to affect the centrally generated pattern of motor instructions to postural muscles. The two amines activate opposite patterns of firing in motoneurons that control postural flexion and extension. These effects require much higher concentrations of amines and probably are accomplished through synaptic contacts between neurons. Thus, amines act both centrally and peripherally to affect posture: the central actions provide specificity, while the peripheral actions enhance the muscle responsiveness.

\section{References}

Augustine, G. J., R. Fetterer, and W. H. Watson (1982) Amine modulation of the neurogenic Limulus heart. J. Neurobiol. 13: 61-74.

Barker, D. L., E. Herbert, J. G. Hildebrand, and E. A. Kravitz (1972) Acetylcholine and lobster sensory neurones. J. Physiol. (Lond.) 226 : 205-229.

Battelle, B. -A., and E. A. Kravitz (1978) Targets of octopamine action in the lobster: Cyclic nucleotide changes and physiological effects in hemolymph, heart and exoskeletal muscle. J. Pharmacol. Exp. Ther. 205: 438-448.

Beltz, B. S., and E. A. Kravitz (1983) Mapping of serotonin-like immunoreactivity in the lobster nervous system. J. Neurosci. 3: 585602.

Benson, J. A., and I. B. Levitan (1983) Serotonin increases an anomalously rectifying $\mathrm{K}^{+}$current in the Aplysia neuron R15. Proc. Natl. Acad. Sci. U. S. A. 80: 3522-3525.

Bowerman, R. F., and J. L. Larimer (1974) Command fibres in the circumoesophageal connectives of crayfish. I. Tonic fibres. J. Exp. Biol. 60: 95-117.

Breen, C. A., and H. L. Atwood (1983) Octopamine-a neurohormone with presynaptic activity-dependent effects at crayfish neuromuscular junctions. Nature 303: 716-718.

Brown, S. K., and D. N. Sherwood (1981) Vascularization of the crayfish abdominal nerve cord. J. Comp. Physiol. A 143: 93-101.

Cooke, l. M., and R. E. Sullivan (1982) Hormones and secretion. In The Biology of Crustacea, H. L. Atwood and D. C. Sandeman, eds., Vol. 3, pp. 206-290, Academic Press Inc., New York.

Davis, W. J. (1976) Organizational concepts in the central motor networks of invertebrates. In Neural Control of Locomotion, R. M. Herman, S. Grillner, P. S. G. Stein, and S. G. Stuart, eds., pp. 265292, Plenum Press, New York.

Delcomyn, F. (1980) Neural basis of rhythmic behavior in animals. Science 210: 492498.

Deterre, P., D. Paupardin-Tritsch, J. Bockaert, and H. M. Gerschenfeld (1981) Role of cyclic AMP in a serotonin-evoked slow inward current in snail neurones. Nature 290: 783-785.

Dudel, J. (1965) Facilitatory effects of 5-hydroxytryptamine on the crayfish neuromuscular junction. Naunyn-Schmiedebergs Arch. Exp. Pathol. Pharmakol. 249: 515.

Dunlap, K., and G. D. Fischbach (1981) Neurotransmitters decrease the calcium conductance activated by depolarization of embryonic chick sensory neurones. J. Physiol. (Lond.) 317: 519-535.

Evans, P. D., E. A. Kravitz, B. R. Talamo, and B. G. Wallace (1976) The association of octopamine with specific neurons along the lobster nerve trunks. J. Physiol. (Lond.) 262: 51-70.

Evoy, W. H., and D. Kennedy (1967) The central nervous organization underlying control of antagonistic muscles in the crayfish. I. Types of command fibers. J. Exp. Zool. 165: 223-238.
Fields, H. (1966) Proprioceptive control of posture in the crayfish abdomen. J. Exp. Biol. 44: 455-468.

Fischer, L., and E. Florey (1983) Modulation of synaptic transmission and excitation-contraction coupling in the opener muscle of the crayfish, Astacus leptodactylus by 5-hydroxytryptamine and octopamine. J. Exp. Biol. 102: 187.

Florey, E., and E. Florey (1954) Uber die mogliche Bedeutung von Enteramin (5-Oxytryptamine) als nervoser Aktionssubstanz bei $\mathrm{Ce}$ phalopoden und dekapoden Crustaceen. Z. Naturforsch. Teil B Anorg. Chem. Org. Chem. Biochem. Biophys. Biol. 9B: 58-68.

Florey, E., and M. Rathmayer (1978) The effects of octopamine and other amines on the heart and on neuromuscular transmission in decapod crustaceans: Further evidence for a role as neurohormone. Comp. Biochem. Physiol. 61C: 229-237.

Gerschenfeld, H. M., and D. Paupardin-Tritsch (1974a) Ionic mechanisms and receptor properties underlying the responses of molluscan neurones to 5-hydroxytryptamine. J. Physiol. (Lond.) 243: 427-456.

Gerschenfeld, H. M., and D. Paupardin-Tritsch (1974b) On the transmitter function of 5-hydroxytryptamine at excitatory and inhibitory monosynaptic junctions. J. Physiol. (Lond.) 243: 457-481.

Glusman, S., and E. A. Kravitz (1982) The action of serotonin on excitatory nerve terminals in lobster nerve-muscle preparations. J. Physiol. (Lond.) 325: 223-241.

Granzow, B., and S. Kater (1977) Identified higher-order neurons controlling the feeding motor program of Helisoma. Neuroscience 2 : 1049-1063.

Grillner, S. (1969) Supraspinal and segmental control of static and dynamic gamma motoneurons in the rat. Acta Physiol. Scand. Suppl. 327: $1-34$.

Grillner, S. (1975a) Locomotion in vertebrates: Central mechanisms and reflex interactions. Physiol. Rev. 55: 247-304.

Grillner, S. (1975b) Some aspects on the descending control of the spinal circuits generating locomotor movements. In Neural Control of Locomotion, R. M. Herman, S. Grillner, P. S. G. Stein, and S. G. Stuart, eds., pp. 351-375, Plenum Press, New York.

Grillner, S. (1981) Control of locomotion in bipeds, tetrapeds and fish. In Handbook of Physiology, V. B. Brooks, ed., Section 1, Vol. 2, Pt. 1, pp. 1179-1236, American Physiological Society, Washington, D. C.

Hartzell, H. C. (1981) Mechanisms of slow postsynaptic potentials. Nature 291: 539 544 .

Kennedy, D., and W. J. Davis (1977) Organization of invertebrate motor systems. In Handbook of Physiology, E. R. Kandel, ed., Section 1, Vol. 1, Pt. 2, pp. 1023-1088, American Physiological Society, Washington, D. C.

Kennedy, D., W. II. Evoy, and J. T. Hanawalt (1966) Release of coordinated behavior in crayfish by single central neurons. Science 154: 917-919.

Kennedy, D., W. H. Evoy, B. Dane, and J. T. Hanawalt (1967) The central nervous organization underlying control of antagonistic muscles in the crayfish. II. Coding of position by command fibers. J. Exp. Zool. 165: 239-248.

Klein, M., E. Shapiro, and E. R. Kandel (1980) Synaptic plasticity and the modulation of the calcium current. J. Exp. Biol. 89: 117-157.

Klein, M., J. Camardo, and E. R. Kandel (1982) Serotonin modulates a specific potassium current in the sensory neurons that show presynaptic facilitation in Aplysia. Proc. Natl. Acad. Sci. U. S. A. 79: 5713-5717.

Kravitz, E. A., S. Glusman, R. M. Harris-Warrick, M. S. Livingstone, T. Schwarz, and M. F. Goy (1980) Amines and a peptide as neurohormones in lobsters. J. Exp. Biol. 89: 159-175.

Kravitz, E. A., B. S. Beltz, S. Glusman, M. F. Goy, R. M. HarrisWarrick, M. F. Johnston, M. S. Livingstone, T. L. Schwarz, and K. K. Siwicki (1983) Neurohormones and lobsters: Biochemistry to behavior. Trends Neurosci. $6: 346-349$.

Kupfermann, 1., and K. K. Weiss (1981) The role of serotonin in arousal of feeding behavior of Aplysia. In Serotonin Neurotransmission and Behavior, B. L. Jacobs and A. Gelperin, eds., pp. 255-287, MIT Press, Cambridge, MA.

Kuwada, J. Y., and J. J. Wine (1979) Crayfish escape behavior: Commands for fast movement inhibit postural tone and reflexes, and prevent habituation of slow reflexes. J. Exp. Biol. 79: 205-224.

Livingstone, M. S., R. M. Harris-Warrick, and E. A. Kravitz (1980) Serotonin and octopamine produce opposite postures in lobsters. Science 208: 76-79. 
Livingstone, M. S., S. F. Schaeffer, and E. A. Kravitz (1981) Biochemistry and ultrastructure of serotonergic nerve endings in the lobster: Serotonin and octopamine are contained in different nerve endings. J. Neurobiol. 12: 27-54.

Miall, R. C., and J. L. Larimer (1982) Interneurons involved in abdominal posture in crayfish: Structure, function and command fiber responses. J. Comp. Physiol. 148: 159-173.

Molinoff, P. B., L. Landsberg, and J. Axelrod (1969) An enzymatic assay for octopamine and other $\beta$-hydroxylated phenylethylamines. J. Pharmacol. Exp. Ther. 170: 253-261.

Otsuka, M., L. L. Iverson, Z. U. Hall, and E. A. Kravitz (1966) Release of gamma-aminobutyric acid from inhibitory nerves of lobsters. Proc. Natl. Acad. Sci. U. S. A. 56: 1110-1112.

Otsuka, M., E. A. Kravitz, and D. D. Potter (1967) Physiological and chemical architecture of a lobster with particular reference to gamma-aminobutyric acid and glutamate. J. Neurophysiol. 30: 725752.

Page, C. H. (1982) Control of posture. In Biology of Crustacea. Vol. 4: Neural Integration and Behavior, D. C. Sandeman and H. L. Atwood, eds., pp. 33-59, Academic Press, New York.

Schwarz, T. L., R. M. Harris-Warrick, S. Glusman, and E. A. Kravitz (1980) A peptide action in a lobster neuromuscular preparation. J. Neurobiol. 11: 623-628.

Selverston, A. I. (1980) Are central pattern generators understandable? Behav. Brain Sci. 3: 535-571.
Sullivan, R. E. (1978) Stimulus-coupled ${ }^{3} \mathrm{H}$-serotonin release from identified neurosecretory fibers in the spiny lobster, Panulirus interruptus. Life Sci. 22: 1429-1438.

Sullivan, R. E., and D. L. Barker (1975) Octopamine increases cyclic AMP content of crustacean ganglia and cardiac muscle. Soc. Neurosci. Abstr. 1: 394

Sullivan, R. E., B. Friend, and D. L. Barker (1979) Structure and function of spiny lobster ligamental nerve plexuses: Evidence for synthesis, storage and secretion of biogenic amines. J. Neurobiol. 8: 581-605.

Thompson, C. S., and C. H. Page (1982) Command fiber activation of superficial flexor motoneurons in the lobster abdomen. J. Comp. Physiol. 148: 515-527.

Viala, D., and P. Buser (1969) The effects of DOPA and 5-HTP on rhythmic efferent discharges in hindlimb nerves in the rabbit. Brain Res. 12: 437-443.

Viala, D., and P. Buser (1971) Modalites d'obtention de rhythmes locomoteurs chez le lapin spinal par traitement pharmacologiques (DOPA, 5-HTP, $d$-amphetamine). Brain Res. 35: 151-165.

Willard, A. L. (1981) Effects of serotonin on the generation of the motor program for swimming by the medicinal leech. J. Neurosci. 1: 936-944.

Zucker, R. S., D. Kennedy, and A. I. Selverston (1971) Neuronal circuit mediating escape responses in crayfish. Science 173: 645-650. 